\title{
Al oído de aquellos interesados en la Reforma de Salud ${ }^{1}$
}

\author{
Ernesto A. Selva Sutter
}

\section{Introducción}

Después de haberse atestiguado en El Salvador la implementación desafortunada de tantas promesas relacionadas con la salud, tales como: planes decenales de salud; propuestas de atención primaria en salud comprensiva; estrategias de salud para todos en el año 2000, para no mencionar los menos o nada prometedores paquetes de atención primaria selectiva ${ }^{3}$; sistemas locales de salud y principalmente los planes de ajuste estructural y las estrategias de inversión en salud preparados por los bancos del sistema financiero internacional, en algunos casos con el apoyo de organismos internacionales de salud como la Organización Mundial de la Salud (OMS) - cuando acaso debería ser al revés- y luego de haberse atestiguado la indiferencia e incluso la agresividad en contra de propuestas locales de reforma (Homedes, Paz, Selva, Solas y Ugalde, 1999; Homedes y Ugalde, 1999; Selva, 1999a; Ugalde, et al., 1999; Ugalde, et al., 1996; Werner, 1995; World Bank, 1993), no queda mucho optimismo porque nuevas propuestas sean

1. El autor agradece a Susana Reyes y Sergio A. Cañas López la valiosa ayuda que le proporcionaron en la edición de este artículo.

2. Jefe del Departamento de Salud Pública de la Universidad Centroamericana "José Simeón Cañas".

3. Restringida es un término que la describe mejor, pero el término usado es cl más conocido. 
atendidas; sin embargo, el presente escrito se elabora para atender la responsabilidad de decir aquello que al respecto es conocido, y existe la necesidad de decirlo por aquellos que no pueden hacerlo.

Son muchas ya las opiniones que destacan que en El Salvador, y quizás en muchas partes del mundo, se impone la necesidad de una reforma del sistema de salud con orientación poblacional. Es decir, con auténtica orientación epidemiológica, privilegiando el enfoque de la colectividad en contraposición al enfoque del individuo; con la mira de rescatar la noción de que la razón fundamental para que las personas decidan o acepten formar comunidades o sociedades es, consciente o inconscientemente, la esperanza de realizaciones colectivas, lo cual tiene siempre como base las condiciones materiales de vida. La finalidad de este tipo de reforma no puede ser más que la realización colectiva, la realización de las necesidades humanas fundamentales en la colectividad, el bienestar humano generalizado o, para ponerlo en términos más prácticos, la expresión óptima de la relación entre el desarrollo con rostro humano y el crecimiento económico (Selva, 1992, 1998).

No está de más insistir en la orientación auténticamente epidemiológica de tal reforma. Aunque la epidemiología clásica, acertadamente señalada como la epidemiología de la exposición (Wing, 1994), siempre ha privilegiado el estudio de la población, lo ha hecho de modo similar al de la biomedicina: partiendo de la exposición de las personas a diversos agentes-causa de enfermedad y tendiendo a aislar individuos y acontecimientos del contexto (Wing, 1994); conceptuando la población como una suma de individuos y reconociendo que la enfermedad y la salud tienen bidimensionalidad, en tanto que presentan una dimensión individual y otra colectiva, o en tanto que son fenómenos biológicos a nivel individual y social a nivel colectivo. Más bien, ha sido la epidemiología socionatural-estructural la que ha dado más solidez al enfoque epidemiológico-poblacional, al demostrar que la salud y la enfermedad individuales son un mito; al establecer que la salud y la enfermedad sólo tienen una dimensión auténtica o fundamental, la cual es colectiva; y al señalar que lo que usualmente consideramos como salud o en- fermedad individuales son expresiones episódicas y carentes de autonomía de procesos colectivos más amplios y fundamentales, que se encuentran articulados a través de diversas vías al contexto en que ocurren y son, al igual que éste, socionaturales en esencia (Selva, 1992, 1998, 1999a).

Lo que consciente o inconscientemente se desea y necesita es una reforma que, entre otras cosas, esté orientada por la epidemiología socionatural y persiga el objetivo de realizar la necesidad humana fundamental para el desarrollo con rostro humano que es la salud (Selva, 1992, 1998). Para ello se impone una revolución saludable que verdaderamente se fundamente en y promueva la equidad, la calidad de atención curativa, paliativa y preventiva, así como la calidez de atención sin discriminaciones de ningún tipo, incluyendo aquella determinada por incapacidad económica. Una reforma que, sin embargo, tome en cuenta elementos económicos y así persiga la eficiencia; que sin ser economicista se preocupe por los ambientes ocupacionales de los ciudadanos; una reforma con respeto al medioambiente, que satisfaga y empodere al consumidor partícipe obligado en la conformación de la misma. Sin embargo, uno de los problemas es que ahora existen múltiples propuestas de reforma que parecen tener los mismos objetivos y estar apoyadas, al menos de acuerdo con ciertos aspectos del discurso que las acompaña, en principios y paradigmas que lucen similares; pero que difieren en lo fundamental y por ello es necesario aclarar muchos componentes de cada una de ellas.

Cualquier trabajador del área de las ciencias de la salud comprenderá las diferencias en términos de prevención, promoción, atención, seguimiento, rehabilitación, etc., que surgen cuando consideramos un caso de diarrea como un caso de desequilibrio electrolítico, que cuando lo consideramos además como lo que realmente es: un estado agudo de deficiencia nutricional del cual probablemente el niño común salvadoreño que lo sufra no se recupere en toda su vida. El ejemplo sirve de apoyo para presentar una primera razón por la cual pueden haber tantas reformas que son, a la vez, tan similares y tan diferentes: el concepto de salud que las orienta. Quizá más correctamente, el concepto sobre los procesos de salud-enfermedad que las orienta. 
2. ¡Reforma ahora! Conceptos y principios que justifican y orientan los principales tipos de reforma

$\checkmark$ Si conceptuamos la salud como una necesidad humana fundamental para el desarrollo y, por lo tanto, como un derecho humano fundamental; si la conceptuamos como una necesidad que sólo puede realizarse relativamente mediante la satisfacción constante de otras necesidades humanas fundamentales (la subsistencia, la protección, el afecto, el entendimiento, la participación, la recreación, la creatividad, la identidad y la libertad), en interacción con acciones especializadas provenientes de y ejecutadas por un sector salud reorganizado y reorientado justamente para la realización de tal necesidad (Selva, 1992, 1998), una reforma del actual sistema de salud en cualquier parte del mundo resulta un imperativo.

Como aceptar tal concepto implica estar consciente de que la realización de una necesidad humana fundamental (la salud, en este caso) no es un fenómeno absoluto o terminado, no hay necesidad de insistir que con tal reforma se persigue una meta cuyo logro implica esfuerzos permanentes y una relación de consolidación-deterioro o cambio constante; ni hay necesidad de insistir en que el logro de esa meta exige esfuerzos colectivos, interdisciplinarios y que es un fenómeno contraentrópico (Selva, 1992, 1998, 1999b).

Tampoco hay que enfatizar entonces la necesidad de que tal tipo de reforma tenga carácter radical, socionatural, epidemiológico-poblacional, interdisciplinario; que exige la investigación constante como fuente de orientación y evaluación -con base en que no existen hechos absolutamente agotados - y que debe tener como su meta la realización colectiva; es decir, el bienestar colectivo (Selva, 1992, 1998, 1999b). Entonces, no es necesario insistir en que la realización de la necesidad humana fundamental salud es motor y objetivo del desarrollo con rostro humano (Selva, 1992, 1998).

$\mathrm{Si}$, por otra parte, concebimos la salud simplemente como la ausencia de enfermedad, o como normalidad, y la enfermedad la concebimos igualmente según términos técnicos propios de la biomedicina, tal concepción podría resultar fácilmente en justificación de otro tipo de reforma caracterizado por la medicalización del sistema y, en el mejor de los casos, por el énfasis en eliminar o paliar la enfermedad del paciente individual, tal como se ha venido haciendo en el mundo biomédico. Este concepto podría justificar reformas que recuerdan aquello que "las cosas deben cambiar para poder continuar como estaban".

Basados entonces en las diferencias entre los conceptos orientadores, y para fines prácticos, diremos que existen ahora dos corrientes o tipos principales de reforma sectorial, o dos clases principales de reforma en nuestro medio. Es sobre la base de esta separación fundamental que continuamos el presente escrito.

Ciertamente, la definición apropiada de salud es la primeramente expuesta, o sea aquella que identifica a la salud como una necesidad humana fundamental para el desarrollo, destaca su carácter dinámico y cambiante, le asigna una causalidad estructural y una esencia socionatural (Selva, 1992, 1998, 1999b); y una reforma del sistema de salud orientada por ella es posible ${ }^{4}$. Sobre todo, resulta sostenible el que sea posible organizar servicios de salud que "gratuitamente" provean coberlura universal de calidad en El Salvador; servicios en los cuales las intervenciones o atenciones sean ofrecidas a través de un proceso de priorización ${ }^{5}$ correspondiente con el perfil epidemiológico presentado; organizar servicios en los cuales las intervenciones sean cumplidas según la necesidad del demandante; los costos sean asumidos solidariamente por aquellas personas que medren del sistema económico imperante y que la recaudación del financiamiento sea fundamentalmente vía impuestos progresivos, como es la experiencia en muchos paises desarrollados y subdesarrollados que han querido afrontar la problemática de esta manera. Esta premisa, que incluye principios importantes, está sustentada por lo discutido en y documentado por diversos estudios, los cuales señalan que en América Latina hay recursos

4. Cabe señalar que la Organización Mundial de la Salud conceptúa la salud como el completo bicnestar físico, mental y social.

5. En Suecia, se priorizó con base en tres principios a los cuales se les asignó importancia en orden descendente: dignidad humana (independientemente de características personales o de funciones sociales), necesidad-solidaridad y costo-efectividad ("The World Health...", 1999). 
suficientes para organizar servicios de salud solidarios y equitativos que cubran las necesidades de atención ambulatoria, incluyendo especialidades; así como servicios hospitalarios básicos cuyo grado de sofisticación dependerá de lo que pueda ofrecer cada país para toda la población, o virtualmente para la totalidad: alrededor de un 90 por ciento de ella (Homedes, et al., 1999; Homedes y Ugalde, 1999; Ugalde, Cañas, Castillo, Paz, Selva y Solas, 1996).

En efecto - tal como lo señalan Homedes y Ugalde (1999)—, Chile, Costa Rica y Cuba son países que han alcanzado tasas virtualmente universales de cobertura con calidad indiscutida en el medio latinoamericano y lo han hecho con menos dinero gastado anualmente per cápita en salud (GPCS) o con poco más del que gasta El Salvador. Citando cifras de 1995 y 1996 (suficientemente buenas para OPS/OMS), Cuba lo ha logrado con un GPCS de 106.00 dólares y un porcentaje del producto interno bruto que se gasta en salud (PIBS) del 9,0 por ciento; Costa Rica con un GPCS de 224.00 dólares y un 8,6 por ciento de PIBS y Chile lo ha logrado con un GPCS de 331.00 dólares y un 8,0 por ciento PIBS (Homedes y Ugalde, 1999). Por otra parte, El Salvador no lo logra con un GPCS de 158.00 dólares y un PIBS de 6,8 por ciento (Homedes y Ugalde, 1999), datos que hablan más de ineficiencia que de imposibilidad; de disparidades en la asignación, que de escasez real de recursos.

Las tasas de inmunización de la niñez en Costa Rica y en Argentina exceden a las alcanzadas en Estados Unidos, a pesar de la menor inversión per cápita en salud (Perez-Stable, 1999).

Además, la premisa antes señalada también está sustentada por estudios que permiten afirmar que la solidaridad y el riesgo compartido son principios básicos no negociables, que cualquier sistema de salud debe preservar y que cualquier modelo de reforma debe incluir (Homedes y Ugalde, 1999). También está fundamentada - a riesgo de parecer romántico- por estudios que dicen que no es ético ni humano darle un carácter lucrativo a las actividades dirigidas a mejorar la salud individual o colectiva, sobre todo CUANDO EL ENRIQUECIMIENTO SE HACE A EXPENSAS DE LA CALIDAD DEL SERVICIO (Homedes y Ugalde, 1999); pero sobre todo -insistimos-, esta posición está respaldada por experiencias como las de Chile, Canadá, el Reino Unido, Costa Rica, Cuba, elc.; así como por lo establecido en diversos estudios que señalan que si el desperdicio y el malmanejo se redujeran en el sector público de los servicios de salud de la mayoría de países de América Latina, la mayor parte de ellos podrían ofrecer paquetes comprensivos de salud a virtualmente toda la población, y no únicamente canastas básicas (Homedes, et al., 1999; Homedes y Ugalde, 1999; Ugalde, et al., 1996; World Health Organization [WHO], 1999). Se sospecha que la obtención, el almacenamiento, la distribución, la receta y el uso de medicamentos constituyen las principales razones del desperdicio prevalente en los sistemas de salud. Existen estudios que indican que la magnitud del malmanejo y del desperdicio relacionada con la cadena de los medicamentos (obtención almacenamiento, distribución, receta y uso) es tal, que en algunos países africanos únicamente 12 por ciento del total de lo invertido por los gobiernos en ellos alcanza al paciente en la forma de medicamentos de buena calidad (Kutzin, 1995).

Otros reportes de aplicación más general señalan que hasta 12 por ciento de la inversión pública en salud (no sólo la inversión en medicamentos) es objeto de malmanejo a través de la utilización inapropiada de medicamentos a través de la obtención, almacenamiento, distribución, receta y uso inapropiado de ellos (Homedes, et al., 1999).

La premisa-principio antes postulada propone un servicio de atención de salud "gratuito", universal, de primera calidad, en el cual las intervenciones ofrecidas (a través de un sistema de priorización) sean cumplidas según la necesidad del demandante y los costos sean asumidos solidariamente por quienes medran del sistema económico imperante, cuya reanudación sea efectuada fundamentalmente vía impuestos progresivos; además, está fundamentada también en las conclusiones obtenidas y publicadas por la OMS en 1999, con base en su análisis de la situación de salud mundial (WHO, 1999).

En efecto, aparentemente retractándose de las acciones propiciadas junto con el Banco Mundial (Word Bank, 1993), la Organización Mundial de la Salud nos proporciona ahora apoyo teórico y práctico (experiencial) enfatizando que: aunque cobertura universal no significa ofrecer y cumplir toda intervención para todos, la cobertura de un sistema de salud debe ser para la población entera; enfatizando también que la manera más equitativa de financiar el sistema, y al mismo tiempo de 
crear acceso igualitario a todas las personas con necesidad comparable, es diluyendo el riesgo de financiamiento mediante un sistema implementado por el gobiemo y fundamentado en la recolección de impuestos generales de una manera progresiva "que rescata proporcionalmente más del ingreso del rico que del pobre" (WHO, 1999). La OMS condena al pago directamente del bolsillo (y consecuentemente a la respuesta de mercado, el seguro privado) como la forma más desorganizada e inequitativa de pago por la atención de salud, puesto que hace recaer sobre el pobre la carga financiera desproporcionadamente (WHO, 1999).

Es claro, entonces, que la reforma orientada hacia la concreción de la salud como necesidad humana fundamental para el desarrollo es la que el sistema de salud de El Salvador exige, que esta es la reforma que los salvadoreños merecemos, incluso la que la mayoría deseamos quizá sin saberlo y la que, por lo tanto, deberíamos tener.

Sin embargo, hay suficientes razones para sospechar que no es ésta la reforma de la que tan insistentemente se ha venido hablando en El Salvador desde más o menos 1993, aunque se le acompañe del discurso que destaca objetivos de equidad, eficiencia, calidad, calidez y satisfacción del usuario; discurso que tiende a ocultar lo discutible de las prescripciones propuestas por sus auspiciadores para alcanzar tales objetivos (Homedes, et al., 1999; Ugalde, et al., 1996).

Esta otra reforma o este otro tipo de reforma que es parte de la imposición de políticas globales por parte de los organismos financieros internacionales, más abiertamente por el Banco Mundial (BM), es la reforma que no nos conviene a los salvadoreños. Y es que el rol protagónico del Banco Mundial y del Banco Interamericano de Desarrollo (BID) se evidenció desde que se implanta- ron de manera más formal los programas de ajuste económico y la restricción del déficit fiscal en los países de América Latina y del Caribe durante la década de los ochenta (Werner, 1995); pero en forma más definitiva, tal protagonismo se evidenció con la publicación en 1993 del documento "Invertir en salud" elaborado por el Banco Mundial con la colaboración de la Organización Mundial de la Salud (World Bank, 1993), en la que se establece lo que algunos consideran los parámetros de lo que podría ser un paradigma para orientar la formulación de políticas, prioridades y estrategias nacionales de salud en los países en desarrollo (Selva, 1999a). Tal forma de orientación o paradigma es de naturaleza biomédica-neoliberalconsumista".

Esta publicación bancaria (World Bank, 1993), la cual ya con su título nos dice mucho de sus orígenes y de sus objetivos - lo cual no nos debería permitir olvidar que banco es banco y su negocio es prestar al interés - es la base para la modalidad operacional de proyectos de reforma sectorial en salud que a su vez forman parte de los programas de modernización del Estado (Selva, 1999a).

Si tomamos en cuenta que las propuestas contenidas en esa publicación del Banco Mundial están presentadas de manera que en una primera lectura resultan con un alto grado de coherencia y sustentación empírica (World Bank, 1993) y que de todas maneras tienen tras de si el peso y apoyo de todos los instrumentos de "persuasión" que las instituciones financieras internacionales nos han demostrado poseer a la hora de influir en la formulación de políticas macroeconómicas de los países en los cuales intervienen, podemos comenzar a encontrar la explicación de por qué la reforma sectorial en salud propuesta por el Banco Mundial es retomada de inmediato y sus posturas,

6. Diferenciamos el consumismo del consumo racional organizado y necesario de bienes materiales para el desarrollo del ser humano. Consumismo implica erigir a los bienes materiales como fines en sí mismos; virtualmente poner la vida al servicio del bien producido como parte de una carrera de producción-distribución desbocada que se entroniza en una sociedad en la que dominan el interés privado egoísta y la intención productivista. Biomédica es aquella corriente dominante en la medicina que en la práctica conceptualiza a la salud como la ausencia de la enfermedad y establece tal ausencia con base en la ausencia de sintomas y signos, y además comprobando que los valores de ciertas características fisiológico-bioquímicas de los individuos se encuentran dentro del espectro de los valores normales correspondientes. La causa última de la enfermedad es, para esta corriente, única, simple, generalmente externa y unidireccional, de carácter biológico o xenobiótico que en la práctica no admite componentes sociales. Tanto la salud como la enfermedad son fenómenos fundamentalmente individuales de acuerdo con esta interprelación; las correspondientes versiones colectivas representan la suma de casos individuales (E. Selva, 1992, 1998, 1999b). 
objetivos, indicadores, etc., son repetidos a coro y citados por muchos "entendidos", aun sin tener plena comprensión de ellos. Esto último podría parecer innecesariamente ofensivo, pero como ejemplo, podría decirse que es difícil encontrar una explicación plena a cómo se obtiene el indicador novedoso ahora citado por muchos y utilizado en tal publicación: los "años de vida ajustados a la discapacidad" (AVADS, DALY en inglés) con base en lo expuesto en los textos del Banco Mundial o con base en explicaciones de conferencistas expertos. Esto es un hecho, aunque por otra parte sea posible llegar según to planteado en los escritos a la conclusión de que tal indicador valora los años de vida perdidos de acuerdo con la edad y el potencial de trabajo de los individuos; de manera que los niños, los enfermos, discapacitados y aquellos que hacen trabajo que no se considera productivo, por ejemplo las mujeres que trabajan en el hogar, quedan en desventaja. También es posible concluir que tal indicador, no es reducible a una medida del número de años de vida saludable que cualquiera pierde al sufrir alguna enfermedad.

Así podemos comenzar a entender por qué este tipo de reforma, cuyas prescripciones no nos permiten dar por seguro beneficios en términos de salud integral, y salud poblacional, pero cuyos costos ciertamente deberemos cubrir, sí es entusiasmadamente considerada y virtualmente retomada por gobiernos y "expertos" locales y la tan necesaria y ansiada reforma orientada por la epidemiología socionatural hacia la realización de la necesidad humana fundamental salud no es siquiera considerada.

Así nos podemos explicar por qué tan de repente (a partir de 1993) una gran cantidad de gobiernos, particularmente aquellos de países con ingresos bajos o medios, comienzan a hablar de una reforma en salud; la cual en diferentes partes del mundo muestra características que coinciden marcadamente, cuando antes gobiernos con orientación similar se negaban a hablar del tema, cuando aún hace sólo quince años podía ser un acto peligroso proponerles reformas de carácter epidemiológico-poblacional que hablaran de equidad, eficiencia, transparencia, calidad y satisfacción del usuario. Quizá la diferencia tenga que ver con que ahora lo especial, además de ese entusiasmo gubernamental colectivo y esa marcada y extendida coincidencia de ideas, es que esta reforma es financiada en tales países por agencias internaciona- les y por bancos multilaterales; que está fundamentada en principios neoliberales; que está siendo implantada por "expertos" extranjeros influenciados fuertemente por la ideología de sus agencias y que tal reforma está inmersa en un contexto de cambios gubernamentales que han surgido como consecuencia de cambios en ideologías económicas, presiones de donantes y restricciones fiscales (Homedes, et al., 1999; Homedes y Ugalde, 1999; Perez-Stable, 1999; Selva, 1998, 1999a; Stoker, Waitzkin e Iriart, 1999; Ugalde, et al., 1996; Werner, 1995).

El planteamiento comprendido en esta sección y la decisión que se pueda tomar con base en él, son elementos críticos para establecer la justificación y la orientación de la reforma o los cambios que decidamos impulsar en el sector salud.

\section{Relación entre la reforma al estilo Banco Mundial, la modernización y la privatiza- ción del sector salud}

El hecho de que el Banco Mundial trate de imponer una reforma en salud no es necesariamente el problema, como tampoco lo es escuchar la propuesta de reforma BM/OMS y los ofrecimientos de financiamiento; tampoco es necesariamente negativo escuchar, analizar y sopesar las condiciones en que se ofrece tal financiamiento. Después de todo es bien sabido que quien paga la música pide la canción y muchos creen que el Banco Mundial es el que paga y que lo hace en muchas áreas y aunque no sea así, al menos ofrece préstamos. Tampoco es negativa una parte del discurso acompañante que incluso en determinado momento parece señalar acertadamente la grandeza de la problemática por superar; en realidad (World Bank, 1993), el problema lo constituyen las prescripciones o estrategias propuestas e incluso impuestas.

El problema -entre otras cosas- es que aunque algunos "entendidos" hagan todo un argumento de que modernización no es lo mismo que privatización y de que ésta no es tan mala, o de que modernizar no implica privatizar; y a pesar de que estrictamente tengan razón en cuanto a que no son lo mismo y en cuanto a que modernizar no implica privatizar, es un poco ingenuo no caer en la cuenta de que la globalización con sello neoliberal que vivimos, las políticas de intervención que la precedieron, la crisis de la deuda externa, los programas de ajuste estructural, las propuestas 
de restricción del déficit fiscal, la modemización global y las reformas sectoriales promovidas por organismos internacionales no solo están íntimamente relacionadas, sino que además tienen a la privatización como uno de sus objetivos; entendiéndose por la mejor expresión de privatización, para que no nos equivoquemos, la transferencia de las funciones $y / o$ la propiedad del sector público a manos privadas, con el fin de crear los muy necesitados espacios para la valorización del capital acumulado en muy pocas manos y con el propósito de satisfacer afanes de lucro o al menos con el fin de reducir los gastos estatales para poder pagar la deuda externa y/o su servicio, la cual fue contraída de manera irresponsable por algunos gobiernos ("La modernización posible",... 1996; Fishlow, 1995; Hinkelammert, s.f.; Homedes, et al., 1999; Homedes y Ugalde, 1999; Kutzin, 1995; Mera, 1992; Selva, 1998, 1999a; Wemer, 1995).

Es ingenuo pensar que la privatización y el neoliberalismo no están intrínsecamente unidos, que tiene mucho sentido imponer el neoliberalismo en nuestros países sin introducir políticas de privatización. Es ingenuo pensar que la única estrategia para alcanzar la privatización es la de proponerla e implantarla en un sólo acto y en su forma más cruda; que la transferencia de funciones a los organismos no gubernamentales, las políticas de cobros al usuario de los servicios públicos o de recuperación de costos en tales servicios, la clara privatización de los servicios auxiliares, las canastas básicas subsidiadas mediante seguros públicos o privados y la contratación de médicos para proveer servicios ambulatorios privados a través de versiones de organizaciones de mantenimiento de la salud (HMO, en inglés) son hechos aislados que no son parte de un programa de privatización de mayor profundidad o crudeza (D. Blumenthal, 1999; Bonnie Booth, 1999; "La modernización posible”, 1996; Fishlow, 1995; Foubister, 1999; Homedes y Ugalde, 1999; Mera, 1992; PerezStable, 1999; Selva, 1999a; Stoker, et al., 1999).

Es ingenuo ignorar que por indicaciones del Banco Mundial muchos de los gobiernos de países pobres que siguen sus dictados están recurriendo a canalizar hacia el sistema nacional organizado de salud el gasto que individuos y familias efectúan directamente de su bolsillo (el cual, actualmente se produce en su mayoría fuera del sistema) para devolverlo a los más pobres de los pobres en forma de paquetes mínimos de salud (Kutzin, 1995).

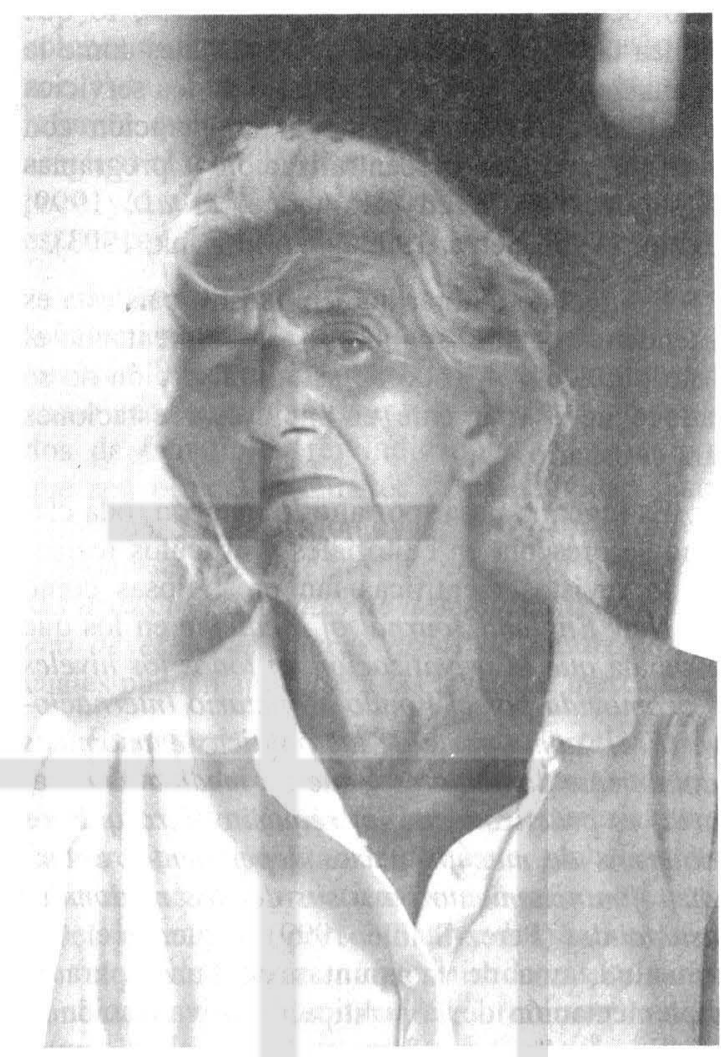

Este gasto puede ser tan alto como para representar entre el 50 y el 80 por ciento del gasto nacional en salud (África Subsahariana e India, respectivamente) (Kutzin, 1995). En El Salvador, el gasto que efectúan directamente de su bolsillo individuos y familias representa aproximadamente 57.5 por ciento del gasto nacional total (Comisión Técnica..., 1998).

Es ingenuo ignorar (puesto que ha sido divulgado ampliamente) que esta prescripción bancaria obedece a que el Banco Mundial ha concluido que el gasto privado en salud tiene el potencial de superar el problema que tienen muchos países de ingresos bajos: financiar el costo de proveer un paquete mínimo de medidas de salud pública y de servicios clínicos a toda la población, pues su costo excede el nivel actual de gasto gubernamental, aun asumiendo que los recursos sean distribuidos y gerenciados adecuadamente (Kutzin, 1995).

En relación con esto, también es ingenuo ignorar que según el Banco Mundial para los países de bajo ingreso, la prescripción es movilizar recursos adicionales (privados) para servicios esencia- 
les ofrecidos públicamente a los pobres, lo que implica también considerar opciones tales como la expansión de los cobros al usuario de los servicios proveídos públicamente; mayor cooperación con el sector privado; descentralización y programas de seguros de salud (Homedes, et al., 1999; Kutzin, 1995; Selva, 1999a; World Bank, 1993).

Es ingenuo ignorar que en nuestro país esta es la tendencia y que, aunque se esté aumentando el gasto público y privado en salud, tal acción no se traduce necesariamente en mejores prestaciones para el usuario.

Es ingenuo pasar por alto lo que con toda claridad se presenta en editoriales y artículos recientes de revistas científicas tan prestigiosas como The New England Journal of Medicine en los que se señala que la privatización en todos los niveles es promovida por el Fondo Monetario Internacional (FMI) como parte de las políticas económicas actualmente dominantes y que tal medida es necesaria, es prácticamente un requisito para que los gobiernos de muchos países dependientes obtengan refinanciamiento para sus deudas nacionales sustanciales (Perez-Stable, 1999); y que, en el sector salud, una de las puntas de lanza para la implementación de la política de privatización la constituyen "nuevas formas de atención conveniente y de tecnología de atención de salud" que emergen de las reformas de salud promovidas por los organismos ejecutores del FMl y que, entre otras, se concretan en sistemas de prestación de servicios que intentan manejar el costo de los servicios de salud, la calidad de la atención y el acceso a estos servicios mediante los llamados sistemas de atención manejada, gerenciada o administrada (Managed Care); los cuales, a su vez, se pueden materializar a través de diferentes modelos de prestación: proveedor preferido, punto de servicio o de HMOs (Perez-Stable, 1999; Selva, 1999a; Stoker, et al., 1999). Este tipo de sistemas se caracteriza por proveer servicios de atención de salud —de corte marcadamente biomédico- bajo el control administrativo de grandes organizaciones privadas y mediante un sistema de pago por capitación (Stoker, et al., 1999).

Es ingenuo pensar que reforma neoliberal y privatización sean separables cuando de diferentes publicaciones, incluyendo alguna de organismos tan autorizados como OPS/OMS, se puede extraer claramente que la privatización de los servicios de salud, entendida como la transferencia de la res- ponsabilidad de la provisión de servicios de salud del sector público al sector privado, es uno de los principios básicos de la reforma de salud (promovida por el FMI o BM y BID) y que este principio podría contradecir el derecho a la salud expresado por la mayoría de constituciones de Latinoamérica (Homedes, et al., 1999).

Más ingenuo resulta no reconocer la relación modemización-privatización en El Salvador, cuando las medidas que el gobierno recién saliente (1994-1999) propuso para tratar de concretar su prioridad de modernizar el estado con el fin de poder competir existosamente en la globalización de los mercados fueron: dolarización de la economía, privatización de los activos públicos, reducción de aranceles, incremento de los impuestos indirectos, reducción del sector público y la expansión de la maquila ("La modernización posible",... 1996). Como ya ha sido documentado también, de estas medidas las que claramente han prosperado son: el incremento del impuesto al valor agregado, el despido de empleados estatales, la privatización de los servicios públicos más rentables $\mathrm{y}$, aunque no tan evidentemente, la reducción real del gasto público, la expansión de la maquila y quizá hasta la convertibilidad y la dolarización ("La modernización posible",... 1996). Este hecho ha permitido que sectores preocupados por y preparados para interpretar la realidad nacional presenten la idea de que en la aclualidad la modernización se equipara con la privatización y sostengan que sí se privatizarán los servicios públicos más rentables (aunque en las acluales circunstancias sea difícil que el país se modernice) porque es una moda impuesta por los organismos internacionales y la ideología neoliberal, y porque el capital nacional $y$ extranjero ve en ellos un área nueva para expandirse y obtener más ganancias y no porque la privatización prometa la superación de los problemas más grandes del país ("La modemización posible",... 1996).

Esta es obviamente una modernización enfrentada desde una perspectiva casi exclusivamente economicista, en términos de menos Estado y más privatización y es una política de modernización del Estado que pretende fundamentarse en un severo cuestionamiento al mismo y a su papel, así como en un proceso de magnificación de las virtudes del sector privado sujeto directamente a las leyes del mercado, pero que obviamente favorece a los intereses del capital financiero y especulativo 
("La modernización posible",... 1996; Hikelammert, s.f.).

Para evitar equívocos debe señalarse que, usando muchas palabras de otros, la modernización del Estado, de El Salvador entero, es necesaria y posible, pero desde otros presupuestos y con una orientación diferente, sin confundir lo nuevo con lo más eficiente y eficaz; con una visión de conjunto, unos criterios técnicos y éticos claros, impulsada por adecuada inversión en capacitación y equipos $y$, sobre todo, con otra mentalidad y con enfoque de nación ("La modernización posible",... 1996).

Y es que la urgencia por privatizar no obedece a tratar de resolver la legítima insatisfacción general de las personas en muchos países del mundo, con respecto a la prestación de servicios y al concomitante cercenamiento de las libertades individuales y públicas (asociadas con la estatización y con la consolidación de burocracias privilegiadas y abusivas) (Mera, 1992). Tampoco obedede a que sea cierto que el sector público sea inherentemente incapaz, ineficiente y corrupto y que el sector privado sea capaz, eficiente y transparente (la verdad es que la contraposición que equipara a la empresa privada con capacidad, eficiencia y honestidad versus la empresa pública con incapacidad, ineficiencia y corrupción no resiste un análisis objetivo) ("La modernización posible",.. 1996). La urgencia por privatizar obedece a la necesidad de crear espacios para la valorización del capital acumulado en pocas manos (Hinkelammert, s.f.; Montoya, 1996).

Privatizar total o parcialmente puede no ser equivalente a modernizar; pero para el Banco Mundial y sus aliados no tiene mucho sentido una reforma en la que no haya reducción absoluta o relativa del gasto gubernamental en salud, una reforma en la cual no existan cargos por servicio o seguros privados para "atención básica", atenciones o canastas básicas constituidas por medidas "costo-efectivas", quizá total o parcialmente subsidiadas, pero únicamente para grupos cada vez más "focalizados" (Kutzin, 1995; World Bank, 1993); por ejemplo para "los más pobres de los pobres" calificados como tales ahora porque pertenecen a una familia con ingresos de 900 colones mensua- les y mañana porque pertenecen a una con 600 colones de ingreso, lo que resulte en un gasto menor. Para el Banco Mundial no tiene sentido una reforma que no conduzca a liberar fondos para asegurar el cumplimiento del pago de la deuda extema y/o a la clara privatización de la propiedad estatal con fines de lucro.

Entonces, es pertinente enfatizar que hacer señalamientos a la privatización - la que puede también llegar a ser una forma de expoliación, como una forma de privar a los sectores desposeídos de beneficios reivindicadores y merecidos, que son ofrecidos a través de la actividad distributiva del Estado (Montoya, 1996) - no equivale a oponerse a la libre gestión del sector privado en sus áreas tradicionales de desempeño o a su derecho de explorar nuevas áreas de desarrollo, las cuales pueden ajustarse a las leyes del mercado.

En síntesis, es crítico plantear la relación de las políticas del Fondo Monetario Internacional y del Banco Mundial o del Banco Interamericano de Desarrollo con programas de ajuste, globalización, modernización y privatización con reformas sectoriales impulsadas por el FMI y los bancos; ésto con el fin de aclarar en determinado caso si sinceramente se quiere implantar una reforma de salud porque los países son incapaces de proveer en forma eficiente servicios ambulatorios y hospitalarios a toda la población, para aclarar si ésta se impulsa debido a la poca calidad de los servicios públicos y privados disponibles particularmente la de aquellos dirigidos a la clase trabajadora y en general a los más desposeídos, como clara evidencia del genuino deseo de reducir y prevenir la carga de enfermedad de nuestras poblaciones, persiguiendo con ello la realización colectiva, la realización de la necesidad humana fundamental salud; o si, por el contrario, se quiere aprovechar el sufrimiento y la insatisfacción genuinos, presentes en la mayoría de la población, así como las claras deficiencias del sistema existente para establecer otro sistema de salud que también tendrá claras deficiencias desde el punto de vista sanitario, tal como las exhibe el sistema de referencia predilecto de quienes apoyan la línea de pensamiento favorecida por el BM, o sea el sistema de atención de Estados Unidos? . Es decir, si por el contrario, se quiere trans-

7. En la sección Sounding Board del 17 de junio de 1999 del The New England Journal of Medicine, Blumenthal destaca que en los últimos 25 años el sistema de atención de salud de los Estados Unidos ha sido plagado por 
formar nuestro sector público de salud, que tradicionalmente, y no sin razón, se ha desarrollado fuera del ámbito de los criterios de rentabilidad, en otra esfera de realización de capital regida por los principios de libre mercado (Hinkelammert, s.f.); es decir, si ese sistema que aunque en forma precaria se mantiene como un testimonio de aceptación de la responsabilidad de proporcionar atención básica de salud de manera universal a nuestras poblaciones de parte de nuestros gobiernos, se quiere desmantelar a favor de la realización del capital.

Si decidimos que lo que está ocurriendo en nuestro país es lo representado por esta última opción, es preciso recordar que es difícil compatibilizar principios de salud pública o de atención de salud ofrecida públi-
Privatizar total o parcialmente puede no ser equivalente a modernizar; pero para el Banco Mundial y sus aliados no tiene mucho sentido una reforma en la que no haya reducción absoluta o relativa del gasto gubernamental en salud,... desde sí y por sí mismo, inducir, animar y defender los comportamientos individuales que puedan resultar en efectos sociales positivos; es decir, que resulten en atención y satisfacción de las necesidades básicas de la población y en facilitar la vida de las mayorias populares ("La modernización posible",... 1996).

El prometido rebalse económico no se produce en la cantidad esperada o necesaria para satisfacer las necesidades de las mayorías porque el individualismo y la lógica de realización de plusvalía se lo impiden ("La modernización posible",... 1996). El mercado a través del individualismo permite un reparto cada vez más desigual de bienes, servicios e ingresos, genera más necesidad y demanda de atención y camente con los principios del mercado; es decir, resulta difícil pensar en o sostener que los servicios públicos privatizados, particularmente aquellos del área de la salud, cubrirán a un mayor número de ciudadanos y con mejor atención (Blumenthal, 1999; "La modemización posible",... 1996; Homedes, et al., 1999; Kutzin, 1995; PerezStable, 1999; Selva, 1999a; Stoker, 1999; Ugalde, et al., 1996; Wemer, 1995; WHO, 1999). En efecto, los conocedores de la problemática económica ya nos han señalado que es vano esperar que el mercado proporcione más y mejor servicio, porque sus virtualidades están orientadas en otra dirección, porque las virtualidades del mercado se fundamentan en intereses particulares $e$ individuales motivados por el afán de lucro ("La modemización posible",... 1996).

El mercado no reparte equitativamente y menos cuando se parte de posiciones desiguales, como ciertamente es el caso en El Salvador; antes de pretender conservarse puro y ser equitativo, el mercado debe liberarse de monopolios, oligopolios y cárteles; tampoco el mercado ha podido, ejerce más presión sobre la estructura económicosocial y la ecológica ("La modernización posible",... 1996). Como señalan Homedes y Ugalde al referirse a la teoría económica del rebalse: "de todos es sabido que, con frecuencia, el desarrollo económico entra en conflicto con la provisión de condiciones favorables para el desarrollo saludable de los ciudadanos; y que son las clases más necesitadas las que se ven más perjudicadas por los efectos negativos que tiene desarrollo económico en los factores socio-ambientales" (Homedes y Ugalde, 1999); en los factores socionaturales en general, decimos nosotros (Selva, 1992).

Si decidimos escuchar el discurso de visiones dogmáticas que tienden a absolutizar la ideología de mercado, es preciso recordar también que los experimentos así orientados ya han producido resultados indeseables (Selva, 1992), y por qué no decirlo, quizá hasta perversos (Hinkelammert, s.f.; Kutzin, 1995; Selva, 1999a).

Justamente en reconocimiento a la influencia del individualismo en sus economías y en su capa-

grandes y crecientes números de personas no aseguradas (15 por ciento); altos y crecientes costos del sistema; la penetrante y esparcida evidencia de calidad subóptima de atención del mismo; restricciones crecientes al acceso a la atención contratada, pérdida de la esperanza con respecto a tener acceso universal a la atención de salud comprensiva, etc. (D. Blumenthal, 1999). Otros autores reafirman que tantos como 43 millones de personas no están aseguradas o cubiertas por algún sistema de salud en Estados Unidos (Bonnic Booth, 1999). 
cidad distributiva, y con la intención de prever las peores consecuencias de tal influencia, es que algunos gobiernos que administran economías de mercado rescatan la necesidad de establecer programas de desarrollo social que repartan los frutos del trabajo, del capital y de los recursos naturales ("La modemización posible",... 1996.; Homedes, et al., 1999). Sin embargo, otros gobiernos, que abandonan la conducción de los países al dogma del mercado libre, soslayan el razonamiento anterior y lo suplantan con programas de compensación social insuficientes para atender siquiera las necesidades seculares, menos las crecientes, de la mayoría de la población ("La modernización posible",... 1996.; Homedes, et al., 1999). Estos programas de compensación social terminan siendo, además de un desafortunado intento de distribución equitativa, parte del intento de vender la idea de que los efectos sociales positivos están garantizados por y devienen automáticamente del libre mercado; sin poderse dejar de destacar que estos programas sociales son parte del intento de desvirtuar que el mercado no es un buen repartidor, encargándose tales programas, en el mejor de los casos, de distribuir lo que supuestamente el mercado debería repartir ("La modemización posible",... 1996).

Si optamos por tomar en cuenta el dogma del libre mercado, recordemos antes de tomar decisiones, que tal visión impone, en principio y para todos los casos, la sustitución de los servicios públicos por privados, sin importar que los unos o los otros sean competitivos o monopolísticos; es decir, sin importar la compatibilidad del resultado de tal sustitución con la ideología que populariza.

Antes de tomar decisiones recordemos también que aquellos que han profundizado en el problema nos han señalado que áreas importantes de la actividad económica no pasan por el mercado, que los llamados bienes públicos - aquellos que pueden ser consumidos o utilizados por muchos simultánea, inconsciente o incluso involuntariamente- no pasan por el mercado; que tampoco la herencia, la transferencia habitual de dinero de proveedores a dependientes dentro de la familia o el trabajo de ama de casa pasan por el mercado; que

tampoco pasan por él donaciones a instituciones y que, irónicamente, en las grandes empresas transnacionales son las decisiones centrales, no el mercado, las que rigen su funcionamiento y que, dentro de ellas, la planificación se extiende y el mercado disminuye su influencia en la medida que crecen y controlan la mayor parte de la actividad económica (“La modemización posible",... 1996). En otras palabras, antes de decidimos es conveniente recordar que el mercado no solamente no es universal, sino que, además, tiene defectos ("La modernización posible",... 1996; World Bank, 1993).

Antes de justificar y orientar cualquier tipo de propuesta de cambio con la noción del mercado libre de corte neoliberal; antes de decidimos por la reforma auspiciada por el Banco Mundial, es crítico tomar en cuenta también que diversos autores y organizaciones, incluyendo al Banco Mundial (BM), ya han señalado que la parte medular del sistema - los servicios de salud- es un mercado imperfecto en el que no pueden aplicarse los principios de libre mercado; que analistas del mismo BM han revisado la teoría económica y han concluido que, en atención a tales fallas del mercado, la intervención gubernamental es un imperativo en el sector, aunque esto no sea válido en otras áreas de la economia; que no es válida la noción de que las fuerzas del mercado por sí mismas pueden producir algún beneficio social óptimo; y que - según analistas de OMS/BM- es evidente que en el área de salud no es posible absolutizar el mercado y las ganancias como referencias ("La modernización posible",... 1996; Fishlow, 1995; Homedes, et al., 1999). 
4. Algunas reflexiones derivadas de las experiencias con la aplicación de la reforma bancomundialista en diversos países, incluyendo El Salvador

Ya ha sido documentado que en su afán por acomodarse a los dictados de la reforma BMOMS, los ministerios de salud (MS) de algunos países afectados por ese tipo de reforma han debido recurrir a arreglos contractuales ventajosos para el sector privado, mediante los cuales lo incentivan y subsidian ${ }^{8}$ (Homedes, et al., 1999; Homedes y Ugalde, 1999). Cabe añadir que la experiencia documentada señala que un prerrequisito importante para que una reforma de corte bancario tenga éxito es una macroeconomía en ascenso y que la tasa de crecimiento económico parece que debe ser al menos de 6 por ciento (Kutzin, 1995).

Esos y otros conocimientos relacionados con u obtenidos de la aplicación de las reformas orientadas por el paradigma del Banco Mundial en otros lugares deben ser retomados para tener las mejores oportunidades de ser exitosos en un medio en que la orientación economicista es dominante, aun cuando se impulsara una reforma hacia la realización colectiva, con carácter socionaturalestructural que se justifica con principios que se corresponden con la satisfacción de las necesidades humanas fundamentales, entre ellas la necesidad salud (Homedes, et al., 1999; Homedes y Ugalde, 1999; Selva, 1992). Por supuesto también debemos tomarlos en cuenta, en atención a ciertas realidades, en el caso de que no pudiéramos intentar implantar una reforma profunda o siquiera universalizar por el momento la cobertura de los servicios y deberíamos optar, en una primera fase, por un proyecto menos ambicioso; por ejemplo, por intentar sentar las bases para la misma y a la vez alcanzar mayor eficiencia y calidad en la prestación de los servicios de salud tratando de consolidar y de aumentar los niveles de cobertura alcanzados.

Citando esas experiencias de reformas inspiradas por los planteamientos de la dupla BM/ OMS (World Bank, 1993), se tiene la oportunidad de despertar el interés incluso de mentes jóvenes, brillantes, con orientación práctica, realista, objetiva y con base técnica, quienes nunca olvidan valorar económicamente toda iniciativa; y se tiene has- ta la oportunidad de sugerir que retomen esas experiencias antes de que decidan el camino de reforma a seguir. Más si se agrega que la reforma del Banco Mundial implica costos en términos humanos, medioambientales y monetarios, y que si nos equivocamos, habrá malgasto de los recursos monetarios públicos que no sería cubierto por el BM (que habría financiado cobrando intereses, una reforma por la que habría presionado), sino por nosotros (Homedes, et al., 1999; Homedes y Ugalde, 1999).

Pero, además, los costos humanos y medioambientales pueden ser realmente incosteables. Los costos mediambientales de una reforma en salud de este tipo se podrán producir vía la explotación directa e intensificada de recursos naturales tradicionalmente utilizados por los desposeídos, cuya proporción, sin duda, se verá aumentada; y por la vía de las exigencias de muchas empresas, particularmente de grandes corporaciones internacionales, para operar en el área de la salud, que probablemente mostrarán tan poca preocupación por la ecología local como la han mostrado sus predecesores en las áreas de: comunicaciones, servicios de alimentación, transporte, etc. Estas compañías predecesoras impulsadas por el individualismo y por el afán de lucro, y aprovechando que el mercado actúa en relación con los recursos naturales como si estos fueran ilimitados, han mostrado una tendencia al inmediatismo virtualmente en todos los países en los que incursionan; el cual, según algunos autores, resulta suicida en El Salvador, debido a la conocida profundidad de la degradación ecológica del pais ("La modernización posible",... 1996; Werner, 1995).

En efecto, pocos discuten en el presente que la causa de la degradación medioambiental, o sea de la contaminación y del agotamiento de los recursos llamados naturales, incluye entre sus condiciones al patrón y a la escala de desarrollo de las siguientes actividades económicas: la producción agrícola e industrial, el consumo de energía y la descarga de desechos ("La modernización posible",... 1996; Werner, 1995). Pocos discuten también que para la gente más pobre del mundo, aquella que depende de los recursos biomasivos para sobrevivir, la destrucción medioambiental puede ser una cuestión de vida o muerte; puesto

8. Los subsidios pueden abarcar organizaciones privadas con o sin fines de lucro. 
que para las sociedades dependientes de la biomasa, el medioambiente es directa y claramente el medio de subsistencia. Además, esto mismo permite plantear que la degradación del medioambiente es determinante de la misma y, consecuentemente, que la conducta de tales empresas favorece la pobreza aunque manejen un discurso que pregona el combate de la pobreza.

Los costos humanos directos del experimento fallido de una reforma bancomundialista podrán derivar de diversas fuentes, incluso de fuentes insospechadas. Por el momento se hará refencia a algunas que no siempre son señaladas como tales, o no se les da la importancia debida.

Primero, los gobiemos latinoamericanos tradicionalmente han aceptado la responsabilidad de proporcionar atención de salud básica de manera universal a nuestras poblaciones, aun cuando ello sea más un principio que una realidad palpable en muchos casos; aunque sea cierto que en la práctica el acceso a ellos sea limitado, no obstante que casi todas las personas tienen derecho a todos los procedimientos y tratamientos ofrecidos (sólo 5 a 10 por ciento no tienen acceso a seguro social o a servicios de los Ministerios de Salud) (Perez-Stable, 1999). Esta responsabilidad desaparecería al implantarse una reforma inspirada por el Banco Mundial y con ello aparecería el problema del no asegurado, del no cubierto de ninguna manera; aparecería la amenaza que en el sistema de referencia (Estados Unidos) es tan grande como 15 por ciento de la población (Blumenthal, 1999) y que en nuestros ambientes tendría probabilidades de crecer mucho más en tal caso. Recuerde el lector que la referencia empírica citada es la primera economía del mundo, en la cual ya se está vislumbrando la necesidad de una reforma de la atención de salud con orientación comprensiva, hacia la cobertura universal, de acuerdo con un artículo ya citado, que aparece en el sounding board del The New England Journal of Medicine (Blumenthal, 1999).

Segundo, los que aumentarán las filas del contingente de los no asegurados o de los que tendrán cobertura disminuida no solamente serán los sin voz como quizá pudiera esperarse, los desposeídos de siempre. La convocatoria a engrosar los rangos será más "democrática" en el caso de que se imponga una reforma inspirada por el Banco Mundial en las condiciones actuales, puesto que incluirá a miembros de la clase media y adinerada de los países latinoamericanos, a personas que proba. blemente estén ahora a favor de la reforma orientada por la ideología del libre mercado, quizás impulsadas por la creencia de que este tipo de reforma implica acceso a nuevas formas de atención de salud de costo conveniente o al menos aceptable, a la luz de sus ingresos (Perez-Stable, 1999).

Los que aumentarán en número serán también miembros de la clase media y adinerada de nuestros países que actualmente cubren sus necesidades de atención médica y de salud pública, personal o familiar, mediante una combinación de ventajas que les permiten hacer uso de los servicios de los ministerios de salud (MS), de los seguros sociales, de seguros privados, incluso de servicios gratuitos o sustancialmente reducidos de parte de médicos o de otros profesionales de salud.

¿Exageración?... Es de conocimiento público que aunque se diga que la macroeconomía de algunos países latinoamericanos es ejemplar, la microeconomía de virtualmente todos los latinoamericanos se siente mal, y es también de conocimiento público que el sueldo que probablemente le será ofrecido por el Instituto Salvadoreño del Seguro Social a un médico especialista a tiempo completo - con una capacitación costosa y sofisticada en un área profesional tradicionalmente considerada bien remunerada - y si se concretan los logros de una lucha gremial exitosa es de 10000 colones mensuales, que es equivalente a 1136.40 dólares en El Salvador, cantidad claramente insuficiente para garantizar la subsistencia de una familia nuclear en alguna ciudad del mundo desarrollado. Sin duda el ejemplo señala claramente esta vulnerabilidad del salvadoreño de ser incluido en los rangos de pobreza o de pobreza relativa, vulnerabilidad que queda claramente al descubierto cuando consideramos que el nivel de pobreza federal (Estados Unidos) es de 1375 dólares mensuales para una familia de cuatro personas ("Children's Health...", 1999).

Pero esto no es todo ni es un hecho aislado en relación con los costos humanos directos. De acuerdo con Pérez-Stable (1999), responsable del editorial, de fecha 8 de abril de 1999, de la revista científica citada antes, el desempleo en general y la pauperización del gremio médico, las limitaciones en la calidad de la capacitación básica o de posgrado; así como la distribución inadecuada de los médicos en nuestros países son factores determinantes para la concreción de un tercer elemento que no es posible dejar fuera de análisis, aquel que 
en un artículo reciente de esa misma revista los autores Stocker, Waitzkin e Iriart (Stoker, et al., 1999) identifican como la exportación de la atención (de salud) manejada, gerenciada o administrada.

En relación con este último elemento, o sea el factor de políticas, modelos o sistemas de prestación de servicios de salud identificados con el término vago de atención manejada, gerenciada o administrada ( $A G)$, debe decirse, particularmente en su calidad de producto de exportación a los países subdesarrollados, que es un derivado perverso de los experimentos económicos orientados por la ideología de libre mercado de corte neoliberal.

Ya se ha hecho referencia a estas aventuras económicas usando términos similares, corriendo el riesgo de parecer innecesariamente severo con quienes las impulsan, y se ha hecho con base en que: primero, tales aventuras han sido impulsadas sin decirle al público al menos una parte importante de la verdadera motivación para imponerlas, o sea el afán de lucro, la necesidad de abrir espacios para la valorización del capital acumulado; segundo, al no decirlo claramente y al retomar otros argumentos se desprestigia innecesariamente a personas e instiluciones de algunos sectores tales como el sector público; tercero porque con el propósilo de apoyar ciertas acciones, particularmente la transferencia de funciones y/o propiedades públicas al sector privado y valiéndose de diferentes medios, se promueve el autodesprestigio de las empresas públicas como parte de tales aventuras, acción que implica malmanejo de los recursos públicos y costos humanos; y cuarto porque en el afán de justificar la existencia y de garantizar la continuidad de tales experimentos a pesar de sus evidentes efectos indeseables, se han desnaturalizado prometedores programas de desarrollo social convirtiéndolos en programas de compensación social los cuales, en realidad, no compensan.

Puede opinarse así porque: primero, está documentado, tal como lo señalan Stocker, Waitzkin e Iriart en su artículo de abril de 1999 publicado en The New England Journal of Medicine (Stoker, et al., 1999), "mientras la preocupación por la dirección que toma la atención gerenciada o administrada crece en los Estados Unidos, ésta se difunde rápidamente a otros países. Desde la mitad de la década de los noventa, las organizaciones de atención gerenciada estadounidenses y los fondos de inversión han penetrado rápidamente en el mercado latinoamericano y esta exportación ha sido relacionada con la privatización y con los recortes en los servicios públicos; instituciones financieras internacionales tales como el Banco Mundial y el Fondo Monetario Internacional usualmente no conceden préstamos adicionales, a menos que tales recortes sean efectivos. Aunque la privatización no conduce necesariamente a la introducción de la atención gerenciada, frecuentemente las dos ocurren juntas e implican la participación de compañías aseguradoras de Estados Unidos y otras corporaciones multinacionales".

Es decir, puede opinarse así porque es clara la relación de los préstamos internacionales, las condiciones para los mismos, y los programas de ajuste estructural y de privatización con la exportación de sistemas de prestación de servicios de salud, cuyos efectos en cuanto al acceso a la atención y a la calidad de la atención son al menos discutibles o inciertos (Blumenthal, 1999; Booth, 1999; "La modernización posible",... 1996; Foubister, 1999; Hinkelammert, s.f.; Homedes, et al., 1999; Homedes y Ugalde, 1999; Klein, 1999; Kutzin, 1995; Montoya, 1996; Selva, 1999a; Wemer, 1995). Además, porque la exportación de la atención gerenciada tiene las características de un "dumping"; de una técnica de "vaciar" en otros mercados productos de dudosa efectividad o al menos no aceptados en el mercado original, ya que los aulores antes citados señalan que los procesos conducentes a implantar sistemas de salud gerenciadas han sido revertidos en países europeos incluyendo al Reino Unido, Holanda y Suecia (Stoker, et al., 1999). También puede opinarse así debido a que algunos autores señalan la reacción negativa que se ha producido en Eslados Unidos contra la atención gerenciada (AG) como una de las motivaciones de las compañías a cargo de la AG para incursionar en los mercados latinoamericanos (Blumenthal, 1999; Booth, 1999; PerezStable, 1992; Stoker, et al., 1999). Debido también a que esos autores destacan que los ejecutivos de tales compañías han identificado a fondos de seguros públicos, particularmente los destinados a la atención de salud existentes en los países latinoamericanos, como una fuerte de financiamiento para las compañías de AG y como una fuente de beneficios muy lucrativos y porque también reportan que tal actividad lucrativa podrá desarrollarse en Latinoamérica con menos restricciones que en otros países y aún con el apoyo de ministerios de salud amistosos (Stoker, et al., 1999). 
Además, porque los sistemas de atención gerenciada cuentan con que el exceso de oferta de médicos y de otros profesionales de salud en América Latina les permitiría hacer contrataciones con sueldos relativamente bajos o disminuidos y cuentan con la crisis económica que afecta al sector público y privado de atención para poder compartir el riesgo financiero con médicos y hospitales; porque, además, su estilo de funcionamiento implica: el uso de incentivos financieros para limitar la atención o para estimular la demanda inducida por el provedor según convenga, enfatizar la limitación de los días de hospitalización, restringir el acceso a los especialistas a menos que el paciente cubra una parte sustancial del costo y limitar el pago a otros médicos o profesionales de la salud, cuyos servicios sean requeridos (Stoker, et al., 1999).

Por desgracia, los ejemplos de cambios diseñados con ideas importadas, cuyos resultados han sido evaluados negativamente por observadores, incluyen la descentralización de los servicios de salud en El Salvador: un proceso todavía en desarollo implantado en 1995 en todo el país que, según el Grupo de Reforma en Salud (GRS) que lo auspicio, pondría el poder de decisión y el control de los servicios públicos más cerca del usuario (Homedes, et al., 1999; Homedes y Ugalde, 1999; Ugalde, et al., 1996). El GRS que gestionó el proyecto de reforma lo hizo sin la participación de entes locales, sin la transparencia necesaria, sin contar con el consenso de los sectores activos de la salud y bajo la presión y la influencia de ideas importadas; más bien casi hizo del secreto una meta (Homedes, et al., 1999; Ugalde, et al., 1996). El GRS fue disuelto en 1996 (Ugalde, et al., 1996).

El GRS, aunque parezca que no viene el caso referirnos a él por estar ya disuelto, diseñó una reforma con orientación bancomundialista sin tomar en cuenta precondiciones y sin adecuación de contenidos; por otra parte, la misma existencia del grupo propició que se dieran pasos desordenados y sin metas claras (Homedes, et al., 1999; Ugalde, et al., 1996).

El contenido de esa reforma que el GRS propuso para el sector salud de EI Salvador incluía las siguientes estrategias: descentralización y privatización como medio para reducir el papel del sector público, la práctica de recuperación de costos en las instalaciones públicas o prepagadas de salud y la provisión gratuita de un paquete mínimo de servicios de salud para los más pobres (Homedes, et al., 1999; Ugalde, et al., 1996).

Aunque el grupo de reforma retomó el concepto de atención primaria en salud selectiva, el cual es un componente básico de la reforma en salud del Banco Mundial y además es un concepto promovido y financiado por USAID en El Salvador a través de los organismos no gubernamentales", existen documentación, declaraciones y razones para pensar que el Grupo de Reforma en Salud estuvo expuesto a las contradicciones de la reforma de los bancos internacionales, BM y BID cuando conoció el señalamiento de estos, acerca de que las intervenciones de atención primaria no tienen mucho impacto en los indicadores de salud que les interesaban a los bancos éstos no estaban dispuestos a prestar para financiar este tipo de medidas (Homedes, et al., 1999; Ugalde, et al., 1996). A cambio y por ello, el Grupo de Reforma en Salud debió considerar un préstamo de $100 \mathrm{mi}$ llones de dólares, 80 por ciento del cual estaba destinado a rehabilitación de hospitales. Aunque finalmente el Banco Interamericano de Desarrollo se retiró de las negociaciones y el GRS fue disuelto cuando el ministro no aceptó las condiciones que trataban de imponer los bancos, dos consecuencias de esta experiencia deben ser traídas a cuenta: la reducción del préstamo del Banco Mundial para salud a $\$ 20 \mathrm{~m}$ para rehabilitación de hospitales y el deterioro de los programas de atención primaria selectiva en El Salvador, los cuales aunque no eran lo mejor, eran algo más que lo que hay ahora (Homedes, et al., 1999; Ugalde, et al., 1996).

En cuanto al tema de la privatización y la descentralización, el Grupo de Reforma en Salud siguió los lineamientos neoliberales de reforma del programa de privatización del país, intensificado en 1991; y de acuerdo con el cual los hospitales públicos, al igual que las universidades, la Administración Nacional de Acueductos y Alcantarillados (ANDA) y Comisión Ejecutiva Hidroeléctrica del Río Lempa (CEL), por ser empresas públicas que requieren ma-

9. La agencia veía a los organismos no gubernamentales como el principal medio para privatizar la atención primaria. Una privatización "suave". 
yor reestructuración o implican riesgos políticos, deberían esperar más de dos años para ser privatizadas (Homedes, et al., 1999; Ugalde, et al., 1996).

El razonamiento del Grupo de Reforma en Salud acerca del problema fue el siguiente: la privatización genera competencia, para sobrevivir en un medio competitivo las corporaciones deben ser eficientes y para alcanzar la eficiencia las empresas necesitan tener mejor rendimiento gerencial y de su personal (Homedes, et al., 1999).

El problema es que, contrario a los postulados teóricos, la privatización no siempre contribuye a la competencia, porque las experiencias demuestran que en las áreas rurales no es posible tener proveedores que compitan ni siquiera para atención primaria; $y$, además, por razones de eficiencia y de distancias geográficas, la posibilidad de competencia de hospitales o de otras instalaciones es nula, incluso en centros urbanos (Homedes y Ugalde, 1999). El problema se agrava porque el sector privado no siempre tiene la infraestructura para ofrecer servicios al sector salud, aun cuando se trata de ofrecer servicios auxiliares como lavandería, cocina, etc.; porque tampoco tiene las cualidades técnicas y gerenciales necesarias (Homedes, et al., 1999; Homedes y Ugalde, 1999). Ciertamente el sector privado no puede sustituir al sector público, no tiene la capacidad para cubrir el vacío que pudiera dejar el sector público (Homedes, et al., 1999; Homedes y Ugalde, 1999).

Es importante señalar que algunos autores destacan que las deficiencias del sector privado limitan su capacidad para ser la solución a la deficiencia de los servicios públicos y a la falta de cobertura (Homedes, et al., 1999; Homedes y Ugalde, 1999). Estas deficiencias en parte responden a la incapacidad o falta de interés del sector público de supervisar y controlar al sector privado, particularmente en situación de reforma. En este sentido, y hace algunos años hacíamos la siguiente pregunta referente a lo ineficaz que podía resultar el papel de un sector público para orientar y controlar a un sector privatizado reformado. Definitivamente, ¿cómo se podía esperar que un sector que no había sido capaz de controlar a un subsector cuando estaba bajo su jurisdicción y bajo su sistema administrativo fuera a ser capaz de controlarlo cuando ya no estaba bajo su jurisdicción y cuando estuviera bajo un sistema administrativo distinto? Es difícil pensar en un papel contralor y rector efectivo, si es ejercido por los ministerios de salud reformados al estilo Banco Mundial.

Además, ahora contamos con reportes de un observador de las reformas del sector salud en algunos países de Europa Oriental (reformas de inspiración neoliberal) que concluye que "es más fácil dirigir el carro desde dentro que desde fuera", también contamos con publicaciones de la Organización Mundial de la Salud que señalan que si el sector público no es capaz de organizar los servicios eficientes de salud es muy probable que por las mismas razones no sea capaz de reglamentar al sector privado, lo que permite concluir a autores como Homedes y Ugalde (Homedes y Ugalde, 1999) que es por lo tanto ilusorio pensar que el aumento de la eficiencia en el sector sanitario puede darse a través de estimular la competitividad en el sector privado.

Estudios en Chile, Brasil, Nicaragua y Guatemala, entre otros, han mostrado que la privatización tiende a favorecer a los pacientes acomodados a costa de los pacientes pobres y que como era de esperarse, ésta ha estimulado la producción de grandes beneficios para las compañías de seguros (Homedes, et al., 1999; Homedes y Ugalde, 1999; Stoker, et al., 1999). Además, en el contexto de la reforma del Banco Mundial, a través de una variedad de mecanismos, el sector público subsidia las primas para seguros privados de ciudadanos afluentes, mientras que los servicios ofrecidos a los pobres decrecen significativamente. Los seguros basados en la comunidad no eliminan problemas de acceso financiero. El uso de sistema de pagos por parte del usuario tiende a excluir más al pobre que al rico del uso de los servicios de salud en general. Definitivamente el incremento en la recuperación de costos ha hecho más difícil el acceso a los servicios públicos para la mayoría pobre (Homedes, et al., 1999; Kutzin, 1995).

La falta de competencia, la ausencia de un ambiente apropiadamente regulador y la corrupción en el sector privado han sido señaladas como razones importantes por las cuales la eficiencia no ha sido consecuencia de la privatización (Homedes, et al., 1999; Homedes y Ugalde, 1999).

El concepto de "paquetes o canastas básicas de salud" llevado a la práctica no ha producido evidencia empírica de que la reducción de los servicios tales canastas tenga un impacto positivo en la equidad. Como reportan Homedes y Ugalde 
(Homedes y Ugalde, 1999), algunos autores ven en la universalización de la canasta básica de servicios de salud un elemento de engaño; porque es atención primaria muy selectiva con nombre de reforma y porque, aunque en teoría aumenta la cobertura con servicios de salud, en la práctica un mayor porcentaje de la población queda descubierta de ellos, debido a que los servicios ofrecidos como parte de esta medida son mínimos y recortados en relación con los ofrecidos antes de la reforma. Es más, se ha podido establecer que si el desperdicio y el malmanejo se redujeran en el sector salud, la mayor parte de países latinoamericanos estarían en la posición de ofrecer universalmente un paquete comprensivo que incluiría atención especializada (Homedes, et al., 1999; Homedes y Ugalde, 1999).

Sólo en determinadas circunstancias el uso de cobros al usuario de los servicios proveídos públicamente puede tener algún impacto en la calidad de servicio, aunque obviamente no en la equidad, esto es: si se le cobra sólo al que puede pagar, si la cuota es adecuada, si lo recaudado se retiene en el establecimiento de salud en que se cobra, si hay otras facilidades tales como bancos en la cercanía de la instalación sanitaria para evitar la depreciación de lo recaudado, si se tiene la capacidad gerencial para invertirlo adecuadamente; es decir, para invertirlo en aquello que sea de beneficio para el paciente (Kutzin, 1995); por ejemplo, teniendo en mente que más que diagnósticos, el paciente busca tratamientos efectivos.

La reforma en salud del Banco Mundial focaliza casi exclusivamente la atención médica en detrimento de otras estrategias que también son costo-efectivas. Asegurar que todos los ciudadanos tengan acceso a atención médica de calidad tiene poco impacto en la reducción de reconocidos factores de enfermedad tales como: medioambientes inseguros; poco acceso a agua potable, particularmente en el área rural y en las zonas urbanas marginales; conductas personales no saludables, poco acceso a vivienda apropiada; pobreza, etc. (Homedes, et al., 1999; Homedes y Ugalde, 1999). Además, la reforma del Banco Mundial ex- cluye otras estrategias que han probado reducir los costos, tales como el control en la compra y la limitación del uso de equipo de alta tecnología, en la compra y uso de los medicamentos que componen la lista de drogas genéricas. Aquí podemos agregar que este tipo de reforma no hace uso apropiado de un recurso que sí podemos tener: el recurso humano en salud. Ignora que los médicos y otros profesionales de la salud no siempre están capacitados adecuadamente para resolver los problemas de salud más prevalentes en el mundo subdesarrollado y que la demanda inducida por el proveedor, especialmente ligada al excesivo número de especialistas en áreas no prioritarias en muchos países subdesarrollados, incrementa los costos (Homedes, et al., 1999; Homedes y Ugalde, 1999; Selva, 1998, 1999a). Ignora que el porcentaje de la población salvadoreña que puede pagar atención es. pecializada ambulatoria $y$ hospitalaria (sin incurrir en el sacrificio de alguna necesidad funda. mental) es tan pequeño, que la posibilidad de organizar un sector salud con vocación lucrativa no se puede vislumbrar en un futuro próximo.

Esto para no señalar que, al menos en El Salvador, los reformadores nunca llegaron a explicarnos plenamente cómo se iba a retomar en la reforma el control de enfermedades transmisibles como malaria, dengue, chagas, tuberculosis o SIDA; y que, además, en sus planes pasaron por alto algunos problemas seculares agravados como producto de la guerra, tales como la precaria atención a los discapacitados físicos y mentales.

Los reformadores tampoco nos han explicado cómo esperan que en un ambiente de reducción del gasto público efectivo en salud, una población mayoritariamente pobre pueda financiar la atención a los problemas reconocidos como propiamente médicos y la atención a los efectos negativos sobre la salud de las poblaciones producidos por la aplicación de políticas energéticas y de políticas en el campo de la agricultura, la industria y de la vivienda, todas ellas de corte neoliberal. 
En resumen, la información señala que en el mejor de los casos es dudoso que la reforma neoliberal pueda tener un impacto positivo en la equidad, la eficiencia, la calidad de cuidados o en la satisfacción del consumidor (Montoya, 1996). Más bien, la evidencia tiende a indicar que el impacto de tal tipo de reforma está siendo negativo (Blumenthal, 1999; Booth, 1999; "La modemización posible",... 1996; Fishlow, 1995; Foubister, 1999; Hinkelammert, s.f.; Homedes, et al., 1999; Homedes y Ugalde, 1999; Klein, 1999; Kutzin, 1995; Perez-Stable, 1999; Werner, 1995).

Es justo decir que hasta ahora el Ministerio de Salud no ha privatizado propiamente la provisión de atención de salud. El año anterior, el Instituto Salvadoreño del Seguro Social (ISSS) comenzó a contratar algunos médicos para la provisión de servicios ambulatorios primarios, mediante una versión de las organizaciones de mantenimiento de salud (HMO, en inglés) (Homedes, et al., 1999). Es muy temprano para evaluar a plenitud este otro paso hacia la privatización, pero ya es posible señalar dos cosas: primero, para el ISSS es esencial que sus costos se reduzcan para justificar tales operaciones, de manera que difícilmente los médicos de las versiones de HMO del ISSS van a tener siquiera una remuneración igual a la que tiene un médico contratado por el Instituto Salvadoreño del Seguro Social. Segundo, basados en las experiencias en Estados Unidos, se puede anticipar que cuando estas organizaciones se enfrenten a dificultades para tener las ganancias esperadas optaran por reducir la atención necesitada por el público.

\section{Una tercera opción para abordar el problema}

Parece que se ha llegado al punto en el que se debe resumir el problema de la siguiente manera: ambos tipos de propuestas o corrientes de reforma del sector salud reconocen y parten de reconocer como obvia la necesidad de que se den cambios significativos en el sector; muchos de los objetivos fundamentales de ellas parecen claros y muestran alto grado de coincidencia a primera vista - mayor equidad y eficiencia, calidad de atención mejorada y que conduzca a un mejor estatus de salud, mayor satisfacción del consumidor y quizá mayor calidez y cobertura universal-; pero es notoria la discrepancia en relación con sus principios fundamentales y consecuentemente en relación con las prescripciones o estrategias que cada una de ellos propone para conseguir esos objetivos.
El paquete de estrategias de la reforma neoliberal auspiciada por el Banco Mundial incluye cualquier combinación de las siguientes: reorientación de las funciones del sector público de salud; descentralización de la toma de decisiones y mayor participación de la comunidad en el proceso; disminución del aparato gubernamental por la vía de privatizar la provisión de servicios; introducción de paquetes de servicios básicos; incremento de la participación privada en el financiamiento del sector y mejoras en el sistema gerencial (Homedes, et al., 1999; Kutzin, 1995; Werner, 1995; World Bank, 1993; "The World Health...", 1999). Sin embargo, podemos agregar que en la práctica se presenta otra estrategia: convertir el paquete de estrategias en los objetivos de la reforma, publicitar que la reforma progresa debidamente con base en que las estrategias se están implementando, más que con base en que los objetivos estén concretados (Homedes, et al., 1999; Homedes y Ugalde, 1999).

Además, parece que hemos alcanzado el punto en que una decisión es imperativa $\mathrm{y}$, con base en estudios en los que hemos participado y están por publicarse, debemos plantear que si se opta por una reforma sectorial hay que asegurarse de que el proceso de definición de la reforma y el contenido de la misma sean los adecuados y que sus componentes sean concretables (Homedes, et al., 1999; Homedes y Ugalde, 1999; Kutzin, 1995; Ugalde, et al., 1996). Ello depende, al menos en parte, de la existencia de determinadas precondiciones ya identificadas, con base en el análisis de los procesos de reforma impulsados por organismos financieros internacionales. Aunque tales estudios refieren directamente a experiencias con reformas orientadas por la ideología que difunde el Banco Mundial, es prudente prestar atención a los resultados obtenidos de ellos antes de intentar cualquier proceso de cambio en el sector salud.

Ciertamente, las tendencias de las precondiciones para el éxito de las reformas auspiciada por los organismos financieros internacionales prevalentes en América Latina no auguran el éxito de tales reformas; en otras palabras, no se dan las precondiciones propicias para ellas (Homedes, et al., 1999; Homedes y Ugalde, 1999; Kutzin, 1995; Ugalde, et al., 1996).

La tendencia es a que las reformas bancomundialistas puedan caracterizarse porque no responden a una iniciativa local o nacional; tampoco se 
apoyan en valores sociales locales o nacionales; su contenido no es definido a través del consenso; los ciudadanos son más objetos que actores en ella; el sistema legal y judicial vigente no favore. ce o permite la ejecución de la reforma; no existe para ellas la posibilidad técnica y financiera, incluyendo la capacidad de gestión, de ejecutar la reforma; y tampoco el sistema político facilita o permite la ejecución de la misma (Homedes, et al., 1999; Homedes y Ugalde, 1999). Cabe destacar que aun medidas prometedoras para muchos, tales como la municipalización de los servicios de salud han fracasado hasta en países como Colombia en donde ha habido un apoyo oficial decidido para la reforma del Banco Mundial, por no existir el apoyo técnico y gerencial necesarios en los municipios, particularmente en los pequeños (Homedes, et al., 1999; Homedes y Ugalde, 1999). También cabe destacar que esta reforma en muchos casos es impuesta en un contexto político que incluye dimensiones constitucionales e institucionales tales como partidos políticos, sindicatos, grupos de presión y el servicio civil que tienen el poder de condicionar e incluso de detener procesos de reforma (Homedes, et al., 1999; Homedes y Ugalde, 1999).

En El Salvador tampoco se cumple en la actualidad la precondición de una macroeconomía en crecimiento a los niveles que lo exige una reforma economicista (Kutzin, 1995); tampoco se observan signos de que ello pueda cambiar dramáticamente a corto plazo.

En este punto, es oportuno destacar otro módulo de conocimiento surgido del proceso de investigación: si se desea el éxito de algún proceso de reforma del sector salud, luego de constatar la existencia de condiciones favorables, es necesario definir acertadamente los contenidos de las mismas y, esencialmente, hay que constatar que el orden en que se implementen los cambios es precisamente el adecuado, particularmente cuando las lineas directrices fundamentales de los modelos de reforma son importadas (Homedes, et al., 1999; Homedes y Ugalde, 1999).

En síntesis, con base en el análisis teórico y de las experiencias con que contamos, podemos plantear que el tipo de reforma del sector salud propuesto por el Banco Mundial no es una opción racional. Proseguir con su implementación no puede menos que ser calificado de temerario; ya que las condiciones consideradas necesarias para pro- nosticar el éxito de tal reforma (precondiciones) no están dadas en El Salvador; que las experiencias con algunos componentes de la misma implementados en El Salvador y otros países no permiten augurar éxitos y que es evidente que los resultados de las reformas bancomundialistas que se están implementando en América Latina son, en el mejor de los casos, cuestionables (Homedes, et al., 1999; Homedes y Ugalde, 1999; Kutzin, 1995).

¿Por qué la apreciación expuesta en este documento es diferente de la de otros, sobre todo de la de los interesados en vender la reforma del Banco Mundial? Al menos en parte porque estamos midiendo el éxito de tal reforma por el impacto que las estrategias propuestas tienen sobre los objetivos propuestos y no por los avances en la implementación de las estrategias propuestas. Porque no estamos haciendo lo que muchos otros hacen: considerar exitosa la reforma del Banco Mundial, porque el sistema de salud se ha privatizado, descentralizado, "modernizado", o debido a que en el sistema se han reducido los costos y se ha aplicado la estrategia de paquetes básicos de salud o porque se ha impuesto el sistema de cobros por servicios públicos, independientemente del impacto en la equidad, eficiencia, calidad, satisfacción de los usuarios y en la realización colectiva.

El camino no es la reforma propuesta por el Banco Mundial; sin embargo, es justo reconocer que en nuestro país tampoco están dadas las condiciones necesarias para la implementación de al menos una "buena aproximación" a nuestra tan soñada reforma con carácter epidemiológico-poblacional y orientada por la epidemiología socionatural hacia la realización de las necesidades humanas fundamentales; debido particularmente a la orientación economicista-consumista de grupos de poder internos y del entorno internacional, pero también debido a la persistencia de muchos prejuicios acerca de la implantación de sistemas con orientación poblacional, a la persistencia de intereses creados de tipo político-económico enfocados a mantener virtualmente invariable el estado de cosas en el pais y también debido a que este tipo de reforma exige como parte de la construcción de sus precondiciones la concreción de una serie de actividades que deben ser implementadas progresivamente a corto y largo plazo y desarrolladas fuera del sector salud, lo que incluye cambios culturales y de valores. Además, porque una parte esen- 
cial del sector salud y de los servicios públicos y privados de atención de salud adolecen de limitaciones o defectos que deberían ser superados antes de intentar implantar una reforma como la que soñamos, aprovechando las virtudes que esa parte esencial del sector ciertamente exhibe.

Por otra parte, no es posible que nos quedemos cruzados de brazos, dado que El Salvador del presente y del futuro obviamente requiere un sector salud renovado, particularmente un sistema público mejorado sustancialmente, al menos en su parte medular: los servicios de salud.

Consecuentemente, nos aventuramos a proponer una tercera forma de abordar el problema; que podría también comprenderse como una forma de dar los primeros pasos para la reforma del sector salud conducente a la realización colectiva y, por otra parte, simplemente como la propuesta de optar por comenzar ahora mismo a introducir cambios que directamente responden a necesidades sentidas, cambios puntuales que pretenden superar problemas específicos; pero con la ventaja de ser principalmente cambios que han sido recomendados en prácticamente todos los reportes y evaluaciones de los sectores de salud de Latinoamerica (Homedes, et al., 1999). Con la ventaja adicional de incluir cambios que, de darse, se convertirían en una base firme para la reforma encaminada a la realización colectiva.

Además, esta tercera propuesta tiene la ventaja de que no nos obliga a renunciar a la orientación que nos ofrece el planteamiento de reforma epidemiológico-socionatural-estructural, conducente a la concreción de la necesidad humana fundamental salud; y sí nos permite retomar las experiencias, en su mayoría negativas, derivadas de la implementación de tantas otras reformas o intentos de reformas, incluyendo aquellas orientadas por la doctrina del Banco Mundial, así como considerar y retomar diversas experiencias y estrategias exitosas o potencialmente exitosas que por ahora han sido olvidadas o relegadas (Homedes, et al., 1999; Homedes y Ugalde, 1999; Kutzin, 1995).
Nos permite también retomar esfuerzos construidos con amplia participación de muchos sectores de la sociedad civil, tal como la Propuesta a la Nación liderada por el Colegio Médico de El Salvador (Colegio Médico..., 1999). Nos permite retomar lo que parece ser el camino más lógico de seguir y que se ha aclarado, en mucho, como producto en virtud del debate originado por los intentos de imposición de la reforma de corte bancomundialista.

La forma más prudente de proceder parece ser la de: primero, escoger la visión y la orientación de la reforma o de los cambios deseados al menos en cuanto a aspectos fundamentales ante la racionalidad dominante (por ejemplo, universalidad-solidaridad en la atención versus la atención individualizada según capacidad de pago); segundo, definir la reforma o los cambios deseados, el contenido y los objetivos específicos de la misma o de los mismos; tercero, asegurar que tales contenidos son concretables al menos en principio y ello equivale, al menos en parte, a asegurarse de la existencia de determinadas precondiciones; cuarto, en caso de no estar dadas tales precondiciones, explorar la posibilidad de construirlas y de ser posible, proceder a construirlas; y quinto, implementar la reforma o los cambios deseados progresivamente y en forma escalonada, acompañados de una evaluación constante fundamentada en la concreción o no de los objetivos identificados.

Al permitirnos proceder prudentemente, esta tercera opción nos permite protegernos de lo que parece ser una fatalidad, pero que es un hecho histórico: no todas las reformas de salud son exitosas, de hecho el éxito es más la excepción que la regla (Homedes, et al., 1999). Los resultados de previas reformas en América Latina sugieren que la reforma de salud no puede ser exitosa sin previos cambios sustanciales en la estructura básica del sector público ("La modemización posible",... 1996; Fishlow, 1995; Homedes, et al., 1999; Homedes y Ugalde, 1999).

Otras ventajas inherentes a la presente propuesta son que toma en cuenta la problemática re- 
lacionada con el tema de la reforma en salud de una manera que permite abordar puntos que pueden ser conflictivos; pero que quizá tienen mayor potencial conflictivo si no son abordados y si no se toman decisiones acerca de ellos (por ejemplo, paradigmas orientadores y justificadores). Además, toma en cuenta consideraciones de tipo económico, así como la influencia neoliberal-consumista del entorno global; que libera el tema de la reforma en salud de las manos de aquellos funcionarios y agentes internacionales y nacionales que lo utilizan como una entretención a menudo lucrativa, aparte de que a algunos de ellos los priva (en el caso de impulsar la reforma en salud del Banco Mundial) de un recurso para aparentar que hacen mucho por los pobres haciendo poco (Homedes y Ugalde, 1999), mientras permiten que se mantengan los niveles presentes de inequidad, desperdicio, malmanejo y hasta de raterismo; es también una propuesta que evita que pospongamos cambios imperativos y, quizá con suerte, evita que nos endeudemos más de lo que estamos.

Cabe señalar, además, que esta propuesta nos permite trabajar orientadamente mientras se conforme un entorno nacional e internacional favorable para la implementación de reformas comprensivas, con orientación epidemiológica-socionatural, con altas probabilidades de contribuir a la realización colectiva.

La construcción de este entorno favorable es posible debido al desarrollo de las siguientes determinantes: primero, las experiencias de los países pobres y de ingresos medios con las reformas sectoriales impulsadas por el Banco Mundial, particularmente con las reformas del sector salud, las cuales tienden a anunciar el inminente fracaso de tales medidas (Homedes, et al., 1999; Homedes y Ugalde, 1999; Kutzin, 1995); segundo, la consolidación de sistemas nacionales de salud de países europeos que después de introducir algunos de los principios de la reforma del BM, particularmente aquellos de atención gerenciada, competencia de mercado y de privatización, dieron marcha atrás al reconocer sus efectos negativos (Stoker, et al., 1999); y tercero, quizá la creciente insatisfacción de los usuarios de sistema de salud que sirve de referencia para las reformas bancomundialistas (el de Estados Unidos), debido a la persistencia y a la intensificación de los efectos de las fallas seculares de las políticas de salud de ese país (Blumenthal, 1999; Booth, 1999; "Children's Health...",

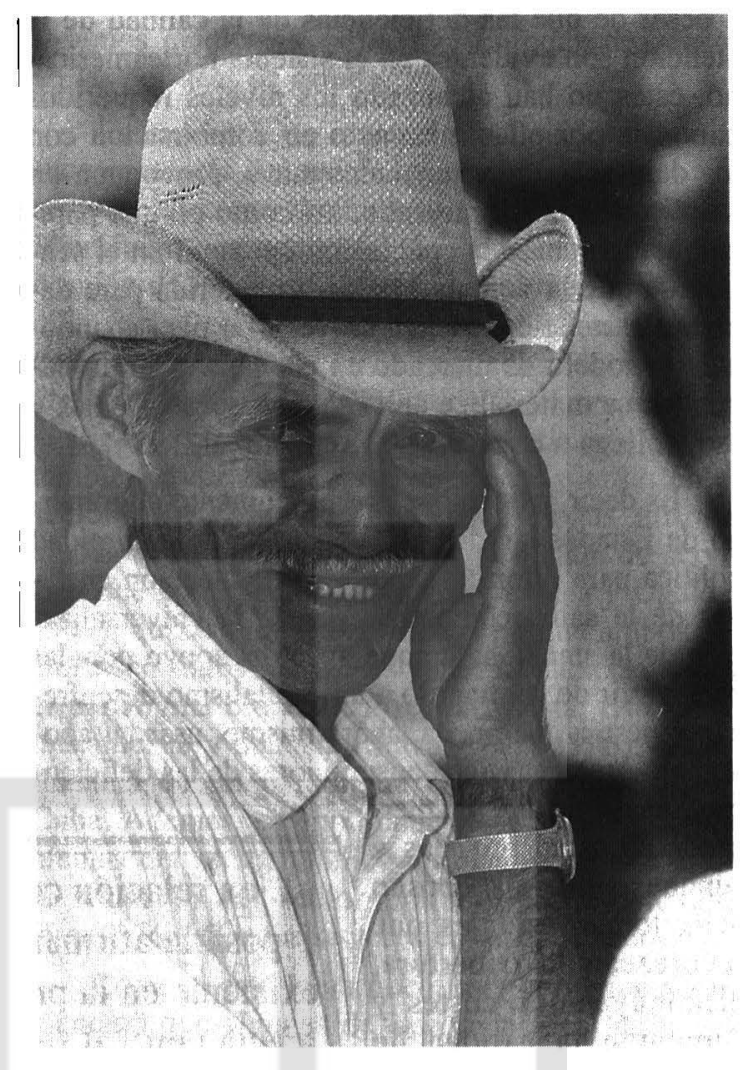

1999; Klein, 1999; Perez-Stable, 1999; Stoker, et al., 1999; WHO, 1999).

Decimos quizá, puesto que según Blumenthal (1999), aunque algunos observadores señalan que el acceso a la atención ya está en crisis en ese sistema debido a que existen más de $\mathbf{4 3}$ millones de personas sin seguro y a los obstáculos administrativos que imponen las organizaciones de atención gerenciada, el problema de acceso a la atención tendrá que agravarse dramáticamente antes de que el público norteamericano rechace la modalidad del abordaje de mercado en la atención de salud y se vuelque en favor de la cobertura universal y de reforma comprensiva de la atención de salud. Además, opinamos así porque también, según el mismo autor, aunque los incrementos en el coste de la atención sean patentes, la fe del público en las soluciones de mercado y la probabilidad de que sean introducidas estrategias correctivas basadas en las leyes del mercado, hacen que un cambio en el sentido de rechazar las fuerzas del mercado como reguladoras de los costes requeriria un incremento de éstos a niveles no previstos, y porque 
a pesar de que las deficiencias de la calidad de la atención son evidentes en el sistema norteamericano, éstas no han alcanzado los niveles requeridos para que por ellas mismas o en combinación con los demás factores señalados antes, provoquen un amplio rechazo al mercado; así como porque parece que tiene base la conclusión del autor en el sentido de que la voluntad política requerida para decretar la atención médica universal o para abandonar el modelo de mercado en ese país es improbable que se materialice antes de una década o más y eso, si llega a concretarse (Blumenthal, 1999).

Es decir, parece que por el momento el gobierno de Estados Unidos no cuenta con la legitimidad política para reformar el sistema de atención en favor de la salud comprensiva y de la universalización de la atención; aunque goce del apoyo popular para servir de contrapeso a un capitalismo desenfrenado; pese a que pueda, ahora mismo, usar tal apoyo para proteger a los consumidores de las deficiencias más serias de los mercados de salud privados y aunque con ese propósito deba tomar medidas que favorezcan la cobertura, disminuyan los costes y aumenten la calidad de atención o no permitan el deterioro de la misma (Blumenthal, 1999).

Ciertamente, el gobiemo de ese país puede y, en atención al clima político, debe aplicar medidas basadas en el mercado, tales como: sistemas más efectivos de ajuste de riesgo, sistemas mejorados para medir la calidad de atención y protección especial para los pobres, los ancianos, enfermos crónicos y los discapacitados, ninguna de las cuales está exenta de costes y de otros problemas.

Sin embargo, esta situación, en unión a los efectos ya sentidos de las deficiencias del sistema de Estados Unidos, que no podrán ser compensados totalmente por tales medidas si el gobierno de ese país las pone en práctica, tiene el potencial de contribuir a la conformación de un entorno más favorable para las reformas de salud deseadas para nuestros países; puesto que al menos disminuirá la aceptación virtualmente acrítica de los mecanismos de mercado como instrumento de distribución de bienes y servicios por parte del público estadounidense.

Nuestra opinión se basa en que tales medidas compensatorias no están exentas de costes o de otros problemas relacionados con la eficiencia o con la equidad y la efectividad. Se basa también en que es casi inevitable el incremento de costos de la atención en el mercado de salud de Estados Unidos, vía los cambios en la tecnología de atención y vía la consolidación de los proveedores; la cual los hace menos susceptibles a demandas de reducción de precios o a la alteración de sus políticas de selección de usuarios y, además, nuestra opinión se fundamenta en la posible aparición de otros factores desestabilizadores de las políticas de atención en Estados Unidos que aceleren los cambios (Blumenthal, 1999; Booth, 1999; "Children's Health...", 1999).

Entre ellos, asociado a la consolidación de los proveedores, al incremento de primas y al incremento de costos de atención de salud, destaca el posible, aunque no probable, colapso de la atención gerenciada que arrastre la industria de seguros en Estados Unidos (Blumenthal, 1999).

Volviendo a nuestra propuesta, es necesario reconocer que, por otra parte, ésta implica el desarrollo de una tarea compleja, exige un esfuerzo nacional, voluntad política y compromisos políticos de nación; y exige, además, esfuerzos interdisciplinarios permanentes.

Concretamente proponemos: los postulados de la epidemiología socionatural-estructural (Selva, 1992), con un enfoque legítimamente poblacional como la visión fundamental orientadora de los cambios. Más específicamente, para un primer gran paso hacia el logro de esa visión, proponemos orientar los esfuerzos a organizar nuestros servicios privados y públicos de salud de forma 
solidaria y equitativa; particularmente orientar los servicios públicos de salud a que equitativa, solidaria y gratuitamente provean cobertura universal de calidad "10, orientarlos a que cubran las necesidades de atención ambulatoria incluyendo especialidades, así como servicios hospitalarios básicos cuyo grado de sofisticación dependa de lo que se le pueda ofrecer a toda la población. Proponemos como referente empírico el caso Costa Rica e incluso el de Canadá, puesto que la misma OMS ahora destaca al seguro nacional de salud de este último país, como una experiencia ejemplar por cuanto ha permitido alcanzar simultáneamente mejor salud y logros económicos (WHO, 1999).

En cuanto a la definición de los cambios o de los contenidos y los objetivos específicos de este tercer tipo de reforma proponemos partir de la base proporcionada por los factores señalados como las razones del fracaso de los países latinoamericanos para no haber alcanzado la cobertura universal, equitativa, solidaria y de calidad deseada y potencialmente alcanzable; asi como por las estrategias exitosas olvidadas o especificamente desplazadas por la implementación de la reforma del Banco Mundial (Homedes y Ugalde, 1999; Selva, 1999a; Werner, 1995).

En cuanto a las estrategias ignoradas o expresamente desplazadas por la implementación de la reforma del Banco Mundial señalaremos que es necesario recuperar las siguientes: (a) Promoción de la salud y prevención de enfermedades. El abandono de estas estrategias ha ocurrido como consecuencia de la focalización de los esfuerzos en la atención médica. ( $b$ ) Información y educación del público (transmisión de conocimiento) y comunicación de masas. (c) Salud medioambiental. (d) Estímulo a iniciativas de reforma locales. (e) Capacitación del recurso humano en administración y particularmente en gerencia de calidad del sector. ( $f$ ) Control del uso o utilización racional de la tecnología de avanzada. ( $g$ ) Atención a la salud ocupacional. (h) Atención al discapacitado. (i) Salud mental. (j) Aplicación de políticas de uso de medicinas esenciales y listados de medicamentos. (k) Aplicación de políticas de economías de escala para adquirir medicamentos. (l) Aplicación de políticas de economías de escala para adquirir insumos médicos y otros. $(m)$ Enfoque de género en las políticas de salud.

En cuanto a las razones a las que obedece la incompetencia del sector salud comenzaremos por señalar, tal como también lo destacan los autores identificados con OPS/OMS, y contrariamente a la opinión de muchos sectores, que al menos en relación con el sector salud es posible afirmar que la deficiencia existente en la prestación de servicios afecta tanto al sector público como al privado y al analizar las causas de las deficiencia por sector, también contrariamente a lo que se piensa, en el sector privado aparecen muchas de las mismas causas de la ineficiencia en la prestación de servicios que en el sector público (Homedes y Ugalde, 1999), quizás en parte al menos porque ambos sectores en todos los países están influenciados por el paradigma biomédico, reduccionista, fisicalista, mecanicista y dualista (Selva, 1992, 1998). La influencia de tal paradigma es notoria incluso en Cuba. Además, es importante rescatar que los problemas del sector público no pueden separarse de la situación del sector privado, que existe una interacción de estos sectores en muchos sentidos.

Como si esto fuera poco, está muy bien documentado que algunas de las principales limitantes del buen funcionamiento del sector salud que afectan tanto a los servicios públicos como a los privados son: la falta de adecuación de los recursos humanos para solucionar los problemas de salud más prevalentes relacionada con la forma en que son capacitados. Por ejemplo, educación flexneriana en carreras de medicina, laboratorio clínico, etc., orientación tradicional de carreras como odontología, enfermería, etc.; creciente abandono de la enseñanza y práctica de los métodos semiológicos para el diagnóstico; poca apertura para el aprendizaje, la práctica y la integración de la medicina alternativa; excesivo número de especialistas por médico general, todos con orientación biomédica; escasez de enfermeras, carencia de administradores de hospitales o de servicios sanitarios en general con entrenamiento universitario, escasez de contables, etc.; énfasis en prácticas terapéuticas costosas y hasta innecesarias en la capacitación médica y en otras áreas de las ciencias de la salud; énfasis en prácticas de diagnóstico costosas

10. En este contexto gratuitamente significa que el usuario recibe la atención que necesite y que pueda ser ofrecida por el sistema de servicios sin cobros directos por el servicio, ya que el usuario habrá pagado ya tal servicio vía impucstos progresivos si es sujecto de impuesto. 
y hasta innecesarias en la capacitación médica y en otras áreas de las ciencias de la salud; deficiencias en la gestión, lo que produce carencia de algunos recursos físicos que hacen inoperantes los existentes. Por ejemplo, falta de reactivos en los laboratorios, placas en las salas de rayos $\mathrm{X}$, etc.; distancia sociocultural entre los profesionales de salud y los pacientes o la población, lo que impide una comunicación adecuada entre médico y paciente o población en su conjunto; bajo nivel de educación en salud en los usuarios que influye en el rechazo a servicios preventivos y en posponer el uso de servicios curativos hasta que aparecen complicaciones; tendencia de muchos pacientes a usar múltiples proveedores y tendencias de los usuarios a demandar medicamentos innecesarios de los proveedores de servicios y la tendencia de los proveedores a satisfacer estas demandas; gastos en salud cuya cuantía se desconoce, que responden a intervenciones curativas de enfermedades prevenibles; tendencia en los planes de inversión y de gasto a ignorar los beneficios económicos de las intervenciones preventivas; baja cobertura de agua potable que afecta a los servicios de salud; baja cobertura con servicios apropiados de disposición de excretas; baja cobertura con servicios apropiados de disposición de desechos peligrosos y basura; poca preocupación por los niveles relativamente altos de desnutrición proteico calórica, por la deficiencia de micronutrientes y por la presencia de cierto tipo de enfermedades infecciosas que no se justifica por los niveles socioeconómicos; falta de políticas o falta de implementación de políticas dirigidas a reducir las tasas de morbi-mortalidad por accidentes, por condiciones de trabajo o por la calidad del medioambiente; falta de mentalidad preventiva, poca atención por la salud preventiva que lleva al fracaso de la misma, la cual responde a la preferencia por parte de las personas que toman decisiones en el sector sanitario de invertir en el sector curativo y a que los políticos y los que dirigen el gasto público consideran más importante financiar programas de desarrollo económico que promocionar la salud.

Además, está documentado que en el sector público la deficiencia en la prestación de servicios responde: al partidismo político y su influencia en el manejo del sector; a las presiones de grupos de interés en la definición de políticas; a la orientación curativa y hospitalaria; a la naturaleza del servicio civil que para protegerse contra las veleidades de los cambios políticos (despidos con cam- bios de gobierno) ha establecido mecanismos proteccionistas que dificultan la aplicación de principios de gestión modema y que reducen la productividad y la capacidad del sistema; a la corrupción expresada de diversas maneras en virtualmente todos los niveles y en muchos ámbitos del sector, la cual se ve facilitada por la incapacidad y la debilidad de los sistemas jurídicos para combatirla; al carácter monopolístico de la prestación de servicios públicos en América Latina, en un ambiente de limitaciones; y a los bajos salarios y a la falta de incentivos y de oportunidades para el perfeccionamiento profesional.

Como si esto fuera poco, en el sector privado aparecen muchas de las causas de deficiencias que en el sector público: (a) El sector privado no es inmune al partidarismo político y a su influencia en el manejo del sector. (b) Oligopolios. A nivel hospitalario en donde se consumen la mayoría de los recursos, es casi imposible crear sistemas competitivos. Por otra parte la competitividad requiere exceso de oferta y el exceso de oferta puede tener un efecto negativo en la eficiencia de los servicios. (c) También oligopolios porque es virtualmente imposible crear sistemas competitivos a nivel ambulatorio en las zonas rurales y en poblaciones pequeñas. (d) Corrupción vía comisiones o referencias de pacientes a especialistas, laboratorios y centros de diagnóstico por imágenes, etc. (e) Corupción vía utilización de servicios e insumos públicos en la práctica privada. (f) Corrupción vía cuentas falsas o infladas de hospitales privados bajo contrato con el sector público (cuando existe un contrato). ( $g$ ) Corrupción vía sistemas contables dobles para evadir impuestos. (h) Corrupción vía la omisión de la prestación de servicios de diagnóstico y terapias necesarias para evitar gastos. (i) Corrupción vía la indicación de servicios de diagnóstico, terapias, intervenciones quirúrgicas innecesarias para aumentar el consumo de lo ofrecido por el sector privado. (j) Corrupción vía demanda inducida innecesariamente por el proveedor. Por ejemplo, alterar un leucograma para que apoye un diagnóstico de apendicitis. $(k)$ Excesivo afán de lucro. $(l)$ Inducción de la demanda innecesaria que es citada en esta forma para diferenciarla un poco de la muy similar demanda inducida por el proveedor a nivel de corrupción, pues la primera todavía cabe dentro de lo legal al ser analizada rigurosamente. $(m)$ Falta de solidaridad. $(n)$ Ofrecer relativamente bajos salarios y pocas oportunidades e incentivos para la formación y el perfec- 
cionamiento profesional cuando actúa como con-

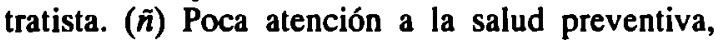
particularmente, poco apoyo a las medidas de carácter epidemiológico-poblacional de su parte.

Superar estos factores que en su mayoría ya han sido señalados como las razones del fracaso de los países latinoamericanos en cuanto a alcanzar cobertura universal, comprensiva y de calidad con sus sistemas de salud y lograr retomar las estrategias desplazadas por la reforma con el sello del Banco Mundial y que la lógica dicta que debemos retomar, equivale, en la opinión de algunos, a una reforma o a una revolución del sector de salud (Homedes, et al., 1999; Homedes y Ugalde, 1999); sin embargo, propongo que lo hagamos como un primer conjunto de cambios que considero que nuestro sistema de salud debe tener, para solidificarlo, de manera que se constituya como base apropiada para cambios más ambiciosos en el sentido poblacional.

Con base en lo expresado al comienzo de este escrito, sería una gran alegría y sorpresa comprobar que algo se ha contribuido con esta publicación; y más aún, comprobar que hemos sido escuchados y atendidos, puesto que el escrito se apoya en el pensamiento y el trabajo propios y de otras personas, tal como se indica en las referencias. En caso contrario nos aferramos al pensamiento de que nada está perdido en la historia, al pensamiento de que tarde o temprano cada idea creativa encuentra oportunidad de desarrollo y añade su color a la llama de la vida. Recordaremos, sobre todo si se imponen reformas de salud orientadas por premisas neoliberales importadas, que el error no comenzó con nosotros ni tiene por qué terminar con nosotros y que no es de la ciencia o de la tecnología que se obtiene la sabiduría, que con ellas, en todo caso, se obtiene el conocimiento y las formas de aplicarlo. La sabiduría, más bien, es cosa de la filosofía y del compromiso con los valores y principios que le dan sentido a la existencia humana.

San Salvador, julio de 1999. (Revisado en mayo de 2000)

\section{Bibliografía}

Blumenthal, D. (1999). "Health Care Reform at the Close of the 20th Century". NEJM, 340: 1916-1920. Booth, Bonnie. (1999). "Wake up on a Growing Problem". AMNews, 5 de julio [http://www.ama- assn.org/sci-pubs/amnews/pick_99/orga0705.htm] (28 junio 1999).

Colegio Médico de El Salvador y colaboradores. (1999). Propuesta a la Nación. Propuesta unificada de politica y estrategia de salud. Documento de trabajo. San Salvador.

Comisión Técnica de Cuéntas Nacionales en Salud. MSPAS. Dirección de Planificación Estratégica y Modernización. (1998). Estimación del gasto nacional en salud en El Salvador durante 1996. Publicaciones MSPAS. San Salvador.

"Children's Health Insurance Program Helpbuild momentum". (1999) (editorial). AMNews, 5 de julio [http/www.ama-assn.org/sci-pubs/amnews/amn_99/ edito0705.htm]

Fishlow, A. (1995). Inequality, Poverty, and Growth: Where Do We Stand? Document Reproduclion Series No. 65, PAHO/WHO, Washington.

Foubister, Vida. (1999). Risky Business. Patient Demand for Specific Drugs Has Squeezed Medical Groups with Financial Responsability for Managing Plans' Drug Costs. AMNews, 5 de julio [Http:// www.ama-assn.org/sci-pubs/amnews/pick_99/ mkta0705.him] (28 de junio de 1999).

Hinkelammert, F. J. (s.f.). El huracán de la globalización: la exclusión y la destrucción del medioambiente vistos desde la teoría de la dependencia. Documento sin fecha y sin indicaciones de lugar de publicación.

Homedes, N., Paz, C., Selva Sutter, E., Solas, O. y Ugalde, A. (1999). "Health Reform: Theory and Practice", manuscrito presentado para su publicación.

Homedes, N. y Ugalde, A. (1999). "Condiciones y condicionantes de salud y reforma". Presentado en Foro APRESAL, Gualemala.

Klein, Sarah A. (1999). "All or Nothing. Managed Care Contracts that Require Participation in all of a "Plan's Products are Drawing the Attention of Antitrust Experts". AMNews, 28 de junio [http:// www.ama-assn.org/sci-pubs/amnews/pick_99/ gvta0628.htm] (21 de junio de 1999).

Kutzin, J. (1995). "Experience with Organizational and Financing Reform of the Health Sector". Current concerns, ARA paper number 8, Divition of Analysis, Research and Assessment, World Health Organization.

“La modernización posible". (1996) (editorial). Estudios Centroamericanos (ECA), 570: 275-287.

Mera, J. (1992). "Privatizaciones en el área de salud". Contribuciones, 3: 131-139.

Montoya, A. (1996). “Globalización... ¿nada más?”. Es tudios Centroamericanos (ECA), 570: 289-305.

Perez-Slable, E. J. (1999). “Managed Care Arrives in Latin America”. NEJM, 340: 1110-1112.

Selva Sutter, E. A. (1992). "Epidemiología socionatural. $\mathrm{Su}$ interacción con un nuevo concepto sobre la calidad de los procesos de salud-enfermedad" (resu- 
men). Publicación D.M.P.S.P., Facultad de Medicina, Universidad de El Salvador.

Selva Sutter, E. A. (1998). "Algunos apuntes sobre el papel de la universidad en la Reforma de Salud", manuscrito presentado para su publicación.

Selva Sutter, E. A. (1999a). "Sobre privatizaciones y otras acciones que afectan al sector salud". Publicaciones del Departamento de Salud Pública de la UCA, Maestría en Salud Pública, San Salvador.

Selva-Sutter, Ernesto A. (1999b). "Más allá de Sagatovsky y Antipov: la causalidad estructural puntualizada". [http://www.uca.edu.sv/facultad/chn/ sagindice.html] (30 de junio de 1999).

Stoker, K., Waitzkin, H., Iriart, C. (1999). "The Exportation of Managed Care to Latin America". NEJM, 340: 1131-1136.

Ugalde, A., Cañas, S., Castillo, C., Paz, C., SelvaSutter, E., Solas, O. (1996). "Reconstruction and Development of the Health Sector in El Salvador
After the 1981-1992 War". Un informe a la Unión Europea en cumplimiento del contrato No. TS 38CT94-03-5 (DG 12 HSMU), San Salvador.

Ugalde, A., Selva-Sutter, E., Castillo, C., Paz, C., Cañas, S. (1999). "The Health Costs of War: Can They Be Measured? Lessons from El Salvador", manuscrito presentado para su publicación.

Werner, D. (1995). Does Primary Health Care Have a Future? Address Leidge Hogeschool, Leiden, The Netherlands. Aviable from Health Wrights, 964, Hamilton Ave. Palo Alto, CA 94301, USA.

Wing, S. (1994). "Limits of Epidemiology". Medicine \& Global Survival, Vol. 1, No. 2.

World Bank. (1993). World Development Report 1993: Investing in Health. New York: Oxford University Press.

World Health Organization. (1999). The World Health Report 1999. Making a Difference. Genova, Switzerland. 